\title{
Game of Blazons: Helping teachers conduct learning situations that integrate web tools and multiple types of augmented reality
}

\author{
Juan A. Muñoz-Cristóbal, Vanesa Gallego-Lema, Higinio F. Arribas-Cubero, Juan I. Asensio-Pérez and \\ Alejandra Martínez-Monés
}

\begin{abstract}
Several studies have explored how to help teachers carry out learning situations involving Augmented Reality (AR), a technology that has shown different affordances for learning. However, these works tend to rely on specific types of AR, focus on particular types of spaces, and are generally disconnected from other technologies widely used in education, such as VLEs or Web 2.0 tools. These constraints limit the possible range of activities that can be conducted and their integration into the existing classroom practice. GLUEPS-AR is a system that can help overcome these limitations, aiding teachers in the creation and enactment of learning situations that may combine multiple types of AR with other common web tools. This paper presents an evaluation study conducted on Game of Blazons, a learning situation carried out by two university teachers using GLUEPS-AR, and framed within two days of outdoor activities in a village in Spain. The evaluation showed that GLUEPS-AR provided an affordable support to the participant teachers to integrate several activities that made use of multiple types of $A R$, common web tools and augmented paper, into a unique learning situation.
\end{abstract}

Index Terms-Learning Technologies, Virtual and augmented reality, Computer Uses in Education, Education, Ubiquitous computing, Mobile environments, Authoring tools

\section{INTRODUCTION}

A N Augmented Reality (AR) system combines and aligns real and virtual objects in a physical environment, and runs interactively and in real time [1]. AR has shown different affordances for learning. For instance, AR can enable ubiquitous, contextual, collaborative and situated learning; may promote learners' sense of immersion and immediacy; is able to enrich physical spaces $^{1}$ with additional information (e.g., making visible the invisible); can bridge formal and informal learning; or enable learning from multiple perspectives [4], [5], [6]. Recent technological

- J.A. Muñoz-Cristóbal and J.I. Asensio-Pérez are with the School of Telecommunications Engineering, Universidad de Valladolid, Paseo de Belén, 15, 47011, Valladolid (Spain) E-mails: juanmunoz@gsic.uva.es, juaase@tel.uva.es

- V. Gallego-Lema and H.F. Arribas-Cubero are with the Faculty of Education and Social Work, Universidad de Valladolid, Paseo de Belén 1, 47011 Valladolid (Spain) E-mails: nesi@gsic.uva.es, quico@mpc.uva.es.

- A. Martínez-Monés is with the School of Computer Science, Universidad de Valladolid, Paseo de Belén, 15, 47011 Valladolid (Spain) E-mail: amartine@infor.uva.es

Manuscript received XX June XXXX; revised XX Oct. XXXX; accepted XX Nov. XXXX. Date of publication XX Nov. XXXX; date of current version $X$ June XXXX

Recommended for acceptance by XXXXX XXXXXXXX XXXXX XXXXX $X X X X X X X X X X$. For information on obtaining reprints of this article, please send e-mail to: reprints@ieee.org, and reference the Digital Object Identifier below.

Digital Object Identifier no. XX.XXXX/XXX.XXXX.XXXXXXX

1. We consider a space as the dimensional environment in which objects and events occur, and in which they have relative position and direction [2]. This definition is not limited to the physical world, also the virtual (computerized) one is considered. Thus, a space would be a container for individuals and their tasks [3], and also for artifacts. advances, especially in mobile devices such as tablets and smartphones, are making AR widely accessible [7]. As a consequence, during the last years, there has been a renewed interest in researching the use of AR in education [5], [6]. Part of this interest focuses on how to help teachers conduct learning situations that make use of AR. The Technology Enhanced Learning research community, under the umbrella of the "orchestration" metaphor [8], has addressed the difficulties faced by teachers when carrying out learning situations supported by complex technological settings. Thus, several authors have explored some of these orchestration aspects, such as how to help teachers create and enact learning situations that make use of AR [9], [10], [6]. However, the existing research works that explore the use of AR in education tend to use only one specific type of AR (e.g., only markers, only geolocation, etc.) in only one specific type of learning space (e.g., only physical augmented environments, only augmented paper, etc.). Such specificity in the existing research works reduce the range of learning situations that can benefit from the affordances of AR [11], [12]. Another aspect important for the orchestration which some authors highlight is how to embed AR into existing classroom practice [13], [12]. Learning effectiveness of AR activities depends on their integration into a heterogeneous set of activities, pedagogies and technologies at different levels (individual, group and class) [12]. Nevertheless, several current research approaches propose AR solutions that are disconnected from technologies commonly used in education such as Virtual Learning Environments [14] (VLEs, 
e.g., Moodle ${ }^{2}$ ) or Web 2.0 tools [15] (e.g., Google Docs ${ }^{3}$ ), thus hampering the integration of such AR systems in the everyday practice of many teachers and institutions. Some authors stress the range of applicability - i.e., the range of possible learning scenarios - as one of the factors to consider for supporting orchestration when designing educational technology [16]. Therefore, there is a need of proposals that support a wider range of applicability of AR [12], and that do not preclude the integration of different types of AR and augmented spaces with other technologies commonly used in the classroom. The research question that we explore in this paper is how technology can help teachers affordably create and enact authentic learning activities that may use different types of AR, different kinds of augmented spaces, and combine AR with other technologies commonly used by teachers.

In this line, GLUEPS-AR [17] is a system aimed at helping teachers create and enact learning situations that can make use of multiple web and AR technologies. GLUEPSAR can integrate multiple existing mobile AR clients (e.g., Layar $^{4}$ ) and several web technologies commonly used in education, such as VLEs and Web 2.0 tools. GLUEPS-AR does not aim at providing novel AR technological features, but rather at helping teachers in the integration of already existing AR solutions into their teaching practice. Since GLUEPS-AR does not oblige teachers to use one specific type of AR, the learning situations deployed ${ }^{5}$ with GLUEPSAR can make use of different clients implementing different types of AR and augmenting different kinds of spaces. Previous evaluation studies around GLUEPS-AR involved the use of particular types of AR in physical environments [17], [18] and did not explore its range of applicability, i.e., whether GLUEPS-AR can support learning activities that make use of multiple types of AR (also augmenting multiple types of learning spaces), and that do not preclude the use of existing learning tools such as those based on common web technologies. Similarly, those previous studies did not tackle the issue of integrating AR-based activities and tools with recurrent technologies found in classrooms, such as those based on common web technologies. Therefore, a new study is required to understand whether GLUEPS-AR overcomes those two limitations

In order to explore the research question, GLUEPS-AR was used, in an evaluation study, to create and enact an authentic learning situation, named "Game of Blazons", by the two teachers of the lecturing team of an undergraduate course for pre-service teachers on Physical Education in the Natural Environment. Game of Blazons was appropriate for the evaluation of GLUEPS-AR, as it demanded the use of marker-based AR and geolocation, the augmentation of physical environment and paper, and the integration of AR with web tools commonly used in education. Such evaluation study is the main contribution of this paper.

The structure of the rest of the document is the following. The next section outlines related approaches in the literature to use AR in education. Section 3 describes the GLUEPS-AR

2. https://moodle.org. Last access December 2017.

3. http://www.google.es/docs/about/. Last access December 2017.

4. https://www.layar.com. Last access December 2017.

5. Throughout this document, we refer with deployment to the setting up of the technological environment that will be used during the enactment. system, highlighting its features to support different types of AR and spaces, as well as to integrate AR with other tools common in education. Section 4 details the evaluation carried out of the support provided by GLUEPS-AR to conduct the Game of Blazons learning situation. Finally, the main conclusions obtained in the study are summarized in Section 5 .

\section{RELATED WORK}

AR technologies can be classified into marker-based or markerless, depending on how the virtual and the real objects are aligned with each other [11], [19] $]^{6}$. In marker-based $\mathrm{AR}$, markers (also referred as tags or labels) are detected by AR devices and used as references to position the virtual artifacts. In markerless AR, the location of the AR device is recognized without using markers (e.g., using a GPS, a wireless network or sensing the physical environment). Both types of AR have been explored in the learning domain, and each one has shown different affordances for learning [11], [21]. For example, markerless AR is normally employed in outdoor activities with mobile devices, offers a good support in collaborative inquiry-based learning [11], and it does not require to prepare the physical setting previously to the activity, such as placing the markers [21]. On the other hand, marker-based AR may foster spatial ability, practical skills in laboratories, or conceptual understanding [11], and it is normally suitable when accuracy in the alignment between the student and some position or object is necessary [21]. The different types of AR have been used in multiple types of scenarios. Thus, several works have employed markerless AR based in geolocation, augmenting geographical locations with virtual content for creating games [4], [22], [23], [24], [25], [26], [27], field trips [28], [29], gymkhanas [30], assessed routes [31], and other kinds of learning situations [32], [33], [34].

Other studies have employed marker-based AR using markers of different kinds for aligning real and virtual objects with each other. Some markers are recognized and identified by the AR system, which associate them with virtual objects. That is the case of fiducial markers [35], which are markers that can be recognized by an image processing module of the AR system. The AR system then tracks the $3 \mathrm{D}$ scene, detects the marker and carries out the actual combination of the physical space with virtual objects. Such markers can be of different shapes, such as circles, squares, or even complex images. Several approaches have used fiducial markers to superimpose virtual objects, e.g., text, 2D images or 3D models, to physical spaces for learning mathematics [36], biology [37], logistic [13], art [38], sciences [39], [40], [41], [42], physical education [43], etc. In other cases, markers store the information (a text, a URL, etc.) used to augment the physical objects or locations. For example, some studies use radio markers based on RFID/NFC or 2D barcodes such as QR codes, that contain information used to augment a physical space for learning

6. Although Pence [19] and later Cheng and Tsai [11] base the mentioned classification on the use of fiducial markers and visual seethrough displays (see van Krevelen and Poelman, 2010 [20], for details about the types of displays), the same classification can be extended to other kinds of markers and displays. 
art, sciences [44], zoology [45], history [46], [47], physical education [48] or for knowing the services and resources of a university campus [49], [50]. Due to the multiple existing definitions of AR in the fields of computing science and educational technology [6], the use of these kinds of markers (2D barcodes, RFIC/NFC) as mere links to virtual content, without combining virtual objects with the physical environment in a single display, is not always considered as AR. Nevertheless, several authors in the literature include such usage under the umbrella of AR [19], [49], [44].

In addition to augmenting physical environments (a classroom, the street, a natural environment, etc.), it is interesting the case of augmenting paper. Paper is an everyday physical object with some characteristics that make it very useful in education [51], [52]: paper is easily handled and annotated; it is easy to carry around, to take home, classroom or outdoor, to pass from one student to another and to the teacher; it affords tiny shifts in position and orientation, and it is also flexible and mobile, thus enabling several kinds of activities; paper is also cheap, and it is present everywhere in multiple educational contexts. Due to the multiples affordances of paper for learning, several research works have explored the use of augmented paper in education during the latest years [12]. For instance, some of these works have augmented sheets or books for enriching them with $2 \mathrm{D}$ or 3D content, or for linking to additional material [32], [51], [53], [54], [55], [12], [56], [57].

All these mentioned research efforts illustrate the interest showed by the Technology Enhanced Learning community during the latest years in the use of $\mathrm{AR}$ in education. However, there is a dearth of works enabling teachers to use different types of AR in their practice [11]. This forces teachers to use multiple systems if they want to conduct activities taking advantage of the different affordances of each type of AR. Only some works enable the combined use of QR codes, RFID tags, and geolocation [58], [59], [60], [61], [62]. However, these systems do not integrate AR with other technologies commonly used in education (e.g., VLEs, Web 2.0 tools, etc.). Santos et al. [21] explored different types of AR (with geolocation, RFID/NFC tags and QR codes), but they used each type in a different study with different systems, which were not integrated with other technologies commonly used in education such as VLEs or Web 2.0 tools. In addition to this problems for augmenting physical environments, augmented paper is scarcely employed in authentic settings, and the existing solutions for its use in education are ad-hoc works, disconnected from other technologies already used by teachers in their practice, and with a limited range of applicability [12]. The next section describes GLUEPS-AR, a system that tries to help teachers put into practice learning situations that integrate multiple types of AR with other web tools widely used in education.

\section{GLUEPS-AR}

GLUEPS-AR [17] is a system aimed to help teachers create and enact authentic learning situations that may involve multiple types of AR, different kinds of spaces, and several web tools widely used in education. GLUEPSAR relies on an architecture based on adapters to integrate multiple systems of different types [17]. Thus, GLUEPSAR may integrate multiple learning design authoring tools, multiple mobile AR clients, multiple VLEs and multiple Web 2.0 tools (see Fig. 1 a). This multi-to-multi approach enables teachers to design learning situations using any of the learning design authoring tools ${ }^{7}$ [63] that GLUEPS-AR can integrate, such as WebCollage [64], ediT2 [65] or Pedagogical Pattern Collector [66]. Using these authoring tools, the teachers can define the different activities, participants, groups and learning resources (depending on the features of the tool used). Then, the teachers can use GLUEPS-AR to import the learning design and specify, using the GLUEPSAR user interface (see Fig. 1 b), characteristics that were not defined in the authoring tool (e.g., information regarding the different spaces involved, such as the positioning of the learning artifacts).

GLUEPS-AR extends to physical spaces the architecture of its predecessor, GLUE!-PS [67], focused on web spaces. The teachers can use GLUEPS-AR to deploy automatically such learning situations in different Ubiquitous Learning Environments (ULEs [68]) which span web and physical spaces (see Fig. 1 a). These ULEs can be composed of several AR systems, such as common mobile AR browsers [69], [70] (e.g., Junaio ${ }^{8}$, Layar, etc.), as well as of multiple web systems widely used in education, such as VLEs (e.g., Moodle), or Web 2.0 tools (e.g., Google Docs, MediaWiki ${ }^{9}$ ). The integration of multiple mobile AR clients enables the support of different types of AR. More precisely, the current GLUEPS-AR prototype supports AR based on geolocation (markerless), as well as in QR codes ${ }^{10}$ and fiducial markers (marker-based). However, the GLUEPS-AR architecture is not restricted to these ones, and the prototype could be easily extended for supporting more types. Any learning artifact in an activity (e.g., a Google Docs document) can be positioned using any of the AR positioning types, and be reused in a subsequent activity using another AR type, or without using AR (e.g., accessing the Google Docs from Moodle). In the GLUEPS-AR user interface (see Fig. 1 b), the teachers can also manage the learning situation and their resources and be aware of the students actions. This awareness is complemented with information about the location of the students during the enactment of the learning situation, which is provided to teachers by means of mobile AR clients. In addition, aiming to help teachers use markers in different spaces, such as in augmented paper, the GLUEPS-AR user interface provides a final printable sheet with the compilation of the markers of a learning situation. It helps the teachers use such markers at enactment time (by printing the sheet directly in order to cut out the markers, or by copying and pasting them in a document). GLUEPS-AR also automates the creation and deletion of web tool instances by means of Tool Mediators [71] such

7. E.g., see a list of learning design authoring tools in the Learning Design Grid website (http://www.ld-grid.org/resources/tools). Last access December 2017.

8. https://en.wikipedia.org/wiki/Junaio. Last access December 2017.

9. https://www.mediawiki.org/wiki/MediaWiki. Last access December 2017

10. We are adopting a wide conceptualization of AR that includes under the umbrella of AR the basic use of QR codes as links to virtual content. 


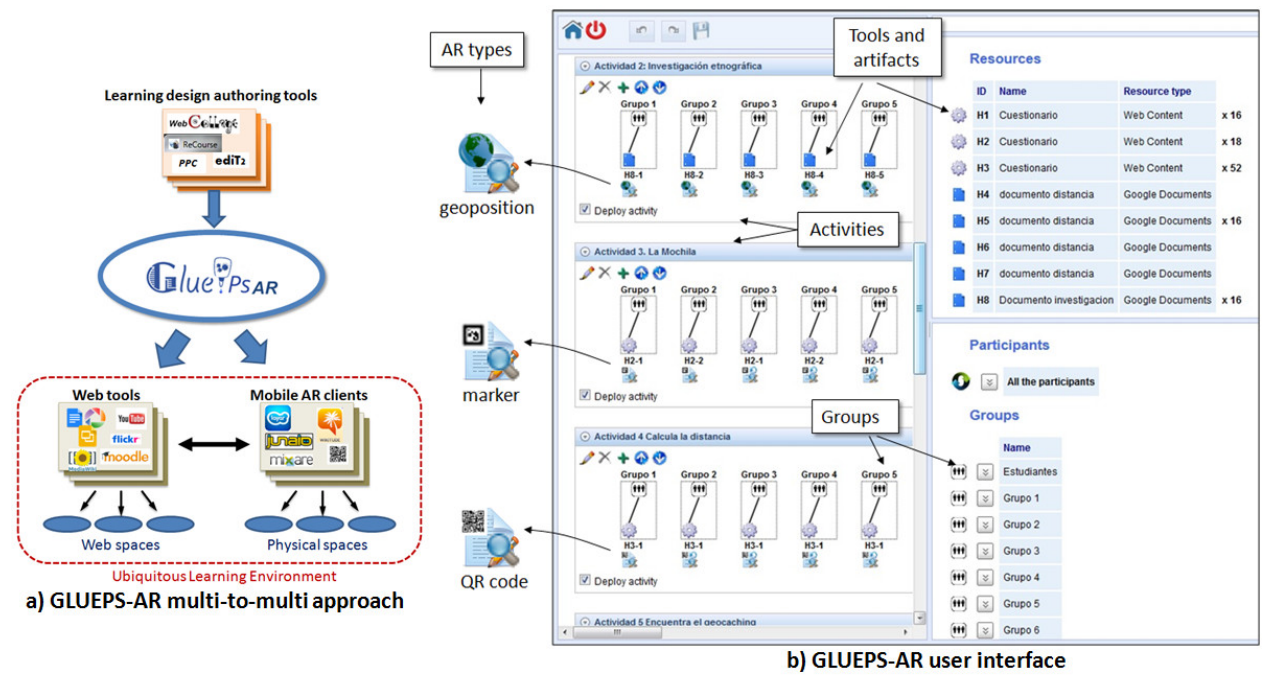

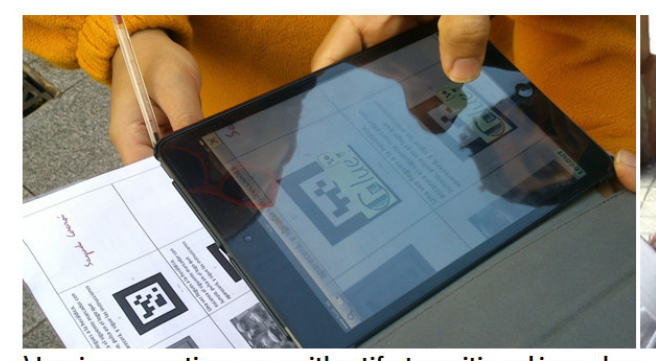

c) Junaio augmenting paper with artifacts positioned in markers

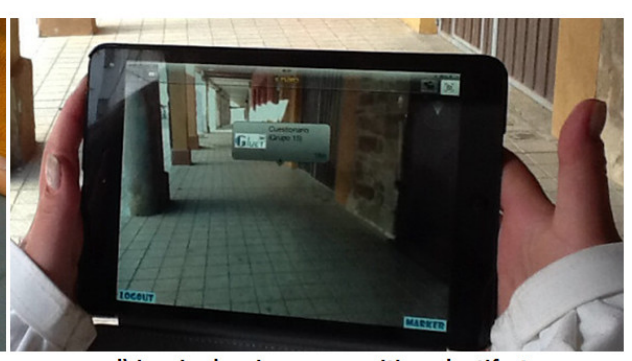

d) Junaio showing a geopositioned artifact

Figure 1. GLUEPS-AR multi-to-multi approach (a). GLUEPS-AR user interface (b), and Junaio user interface showing artifacts positioned in fiducial markers (c) and geolocated (d), all of them captured during Game of Blazons

as GLUE! [72], the one implemented in the prototype. In addition, GLUEPS-AR is designed to support collaborative learning, even if the authoring tool or the web and AR tools employed do not support it natively. Thus, by using GLUEPS-AR, a class can be structured in groups of students. Then, GLUEPS-AR deploys the learning situation in such a way, that during the enactment, different groups can access different tools and resources in the same space position (e.g., in the same fiducial marker or the same geolocation). Fig. 1 shows examples of the use of two different types of AR in two spaces in the Game of Blazons learning situation: marker-based AR with markers augmenting paper (Fig. 1 c), and markerless AR with a learning artifact geolocated in a physical environment (Fig. 1 d). In both cases, AR enables the access to Web 2.0 artifacts from such physical spaces (not visible in the figure).

Table 1 shows the different features of GLUEPS-AR that can aid teachers in the challenge of creating and enacting learning situations involving different types of AR, augmenting different types of spaces, and integrating AR activities into the existing classroom practice. As Table 1 illustrates, the GLUEPS-AR multi-to-multi approach is a key factor in such challenge, helping teachers create and combine multiple activities that may use different types of $\mathrm{AR}$ and web tools, extending thus the possible range of applicability with respect to alternative approaches. The next section describes the evaluation carried out to assess the support provided by GLUEPS-AR to this challenge.

\section{Evaluation}

We have carried out an evaluation to explore the research question that drives our work: how can technology help teachers affordably create and enact authentic learning activities that may use different types of AR, different kinds of augmented spaces, and combine AR with other technologies commonly used by teachers?

For the evaluation, we studied how a lecturing team, with the help of GLUEPS-AR, created and enacted a learning situation called "Game of Blazons". This section describes the learning situation carried out, as well as the evaluation method and results.

\subsection{Game of Blazons}

Game of Blazons is a learning situation that was created and enacted in October 2013 by the two teachers of an undergraduate course on Physical Education in the Natural Environment, corresponding to the last year (out of four) of a Degree in Primary Education for pre-service teachers of a Spanish university. The teachers were the main teacher of the course and an assistant, with pedagogical background and teaching expertise of 22 and 1,5 years respectively. The learning situation was enacted with a class of 47 students. The teachers used the WebCollage authoring tool to create a sequence of collaborative learning activities, indicating also the resources to use and the configuration of groups of students. Then, they imported automatically such design into GLUEPS-AR. Using the GLUEPS-AR user interface, they fine-tuned the design (creating and configuring the 
Table 1

Specific GLUEPS-AR features to help overcome the challenge of using multiple types of $A R$, augmenting different spaces and integrating $A R$ activities into the existing educational practice

\begin{tabular}{|l|l|l|}
\hline $\begin{array}{l}\text { Aspects of } \\
\text { the challenge }\end{array}$ & GLUEPS-AR features & $\begin{array}{l}\text { Current prototype } \\
\text { implementation }\end{array}$ \\
\hline $\begin{array}{l}\text { Creation and } \\
\text { enactment of } \\
\text { learning } \\
\text { situations } \\
\text { that use AR }\end{array}$ & $\begin{array}{l}\text { Helping create and } \\
\text { deploy learning } \\
\text { situations in different } \\
\text { ULEs. Providing a user } \\
\text { interface and runtime } \\
\text { information to help } \\
\text { manage the learning } \\
\text { situations and be aware } \\
\text { of the students' actions. }\end{array}$ & $\begin{array}{l}\text { Integrates 3 authoring } \\
\text { tools (WebCollage, ediT2, } \\
\text { PPC) and any authoring } \\
\text { tool supporting IMS LD } \\
\text { level A; provides a user } \\
\text { interface to manage the } \\
\text { learning situations; } \\
\text { provides AR user } \\
\text { awareness. }\end{array}$ \\
\hline $\begin{array}{l}\text { Use of } \\
\text { multiple } \\
\text { types of AR } \\
\text { and } \\
\text { augmented } \\
\text { spaces }\end{array}$ & $\begin{array}{l}\text { Enabling the use of } \\
\text { multiple AR systems, } \\
\text { which can support } \\
\text { different types of AR } \\
\text { and can be suitable for } \\
\text { augmenting different } \\
\text { spaces. }\end{array}$ & $\begin{array}{l}\text { Integrates 4 mobile AR } \\
\text { clients (Junaio, Layar, } \\
\text { Mixare, any QR code } \\
\text { reader); supports 3 types } \\
\text { of AR (fiducial markers, } \\
\text { QR codes, geolocation); } \\
\text { provides a list of markers } \\
\text { ready to be } \\
\text { copied/pasted in paper. }\end{array}$ \\
\hline $\begin{array}{l}\text { Integration of } \\
\text { AR with } \\
\text { other } \\
\text { activities of } \\
\text { the existing } \\
\text { educational } \\
\text { practice }\end{array}$ & $\begin{array}{l}\text { Enabling a seamless } \\
\text { integration of AR } \\
\text { systems with multiple } \\
\text { web tools, such as VLEs } \\
\text { or Web 2.0 tools. }\end{array}$ & $\begin{array}{l}\begin{array}{l}\text { Integrates 2 VLEs: } \\
\text { Moodle and Mediawikic } \\
\text { Integrates more than 20 } \\
\text { third party tools and } \\
\text { artifact types: Google } \\
\text { Docs, Google Slides }\end{array} \\
\text { several widgets, 3D } \\
\text { models, etc. }\end{array}$ \\
\hline
\end{tabular}

a. http://www.imsglobal.org/learningdesign/. Last access December 2017.

b. http://www.mixare.org. Last access December 2017.

c. http://www.mediawiki.org. Last access December 2017.

d. http://www.google.com/slides/about/. Last access December 2017.

different tool instances, defining the positioning type and the specific position of the different learning artifacts, etc.). Finally, using the "deploy" button provided by GLUEPSAR, they deployed the design into a ULE composed of Moodle, some Web 2.0 tools, the Junaio mobile AR client, and any common QR code reader.

Game of Blazons was carried out mainly in Cervera de Pisuerga, a small village situated in a mountainous area in northern Spain, which was a thriving town in the Medieval times. Game of Blazons was part of a set of activities that spanned two days of work with the students in the village and its surroundings. Such work was focused on acquiring skills for preparing physical education activities in the natural environment for Primary school pupils (e.g., camping activities). Those two days also included several activities besides Game of Blazons (ethnographic, cultural and social activities, trekking, orienteering, canoeing, etc.). Moreover, the multiple activities carried out in situ were preceded by a lecture in the classroom, and by online work using Moodle. The main teacher had conducted the previous years a similar set of activities in the surroundings of Cervera de Pisuerga, although this was the first time he carried out Game of Blazons. During Game of Blazons, the use of existing technologies was required because the teachers, in addition to innovating and enriching the learning experience by using technology, aimed to show the students a

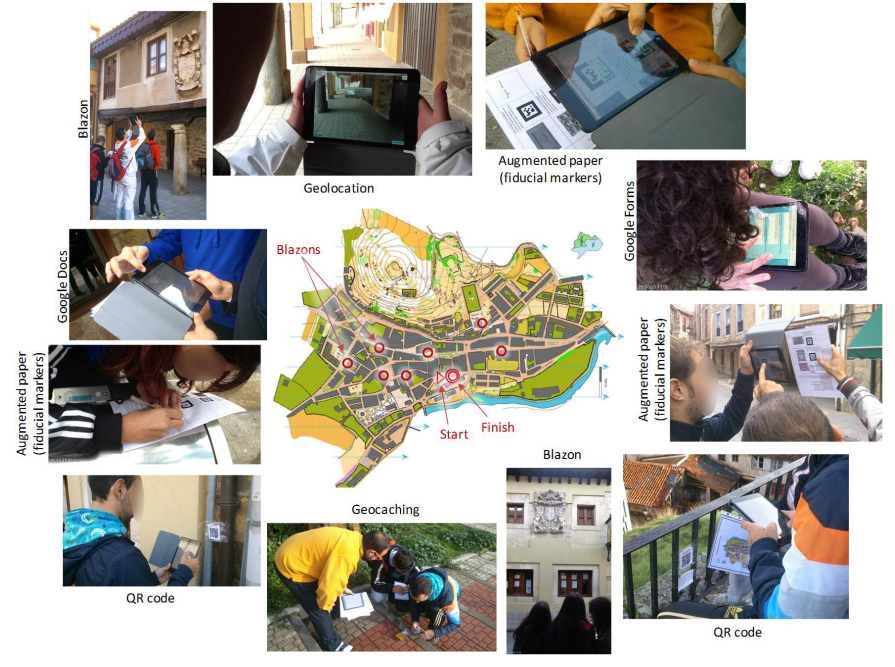

Figure 2. Game of Blazons: Orienteering map of Cervera de Pisuerga and snapshots of the learning situation

possible range of tools they could use in the Primary school. The enactment of the learning situation was led by the assistant teacher, who explained what to do to the different groups of students.

Game of Blazons was conducted in groups of three students (and one group of two students since they were 47). The aim of the learning situation was to find, using orienteering skills, seven stone blazons (i.e., coat of arms, heraldic shields) chiseled in the walls of different village's buildings ${ }^{11}$, and perform close to each blazon a specific activity, delivered to the students by means of AR. Such activities were focused on acquiring and reinforcing knowledge and skills about the natural, cultural and ethnographic environment, as well as about physical education in the natural environment. Also, the students had to find out the names of the blazons on their own (e.g., searching in the Web, or interacting with locals). The time assigned to each group to complete the situation was 1,5 hours. Each group received:

- A tablet with $3 \mathrm{G}$ connection and with the following installed apps: the Junaio AR browser, a QR code scanner $^{12}$, a geocaching ${ }^{13}$ app $^{14}$, and a drawing app ${ }^{15}$ with the map of the Village. The students could also use their own mobile phones (the tablets ensured that each group was provided with a tested device, with all the required apps and resources installed, and good internet connectivity).

11. Cervera de Pisuerga preserves several stone blazons in its buildings since the Middle Ages.

12. http://www.neoreader.com. Last access December 2017.

13. Geocaching is a public gymkhana based in GPS coordinates. People hide little "treasures" (called geocaches), and publish their position in a website (there are various geocaching communities, such as https://www.geocaching.com). The person who finds a treasure has to write her name in a paper included in the treasure, and optionally, replace an object of the treasure with another object.

14. Lookin4Cache (http://www.looking4cache.com) in iOS devices and c:geo (http://www.cgeo.org) in android ones. Last access December 2017.

15. LINE Brush, available at http://line.me/es/family-apps. Last access September 2016. 


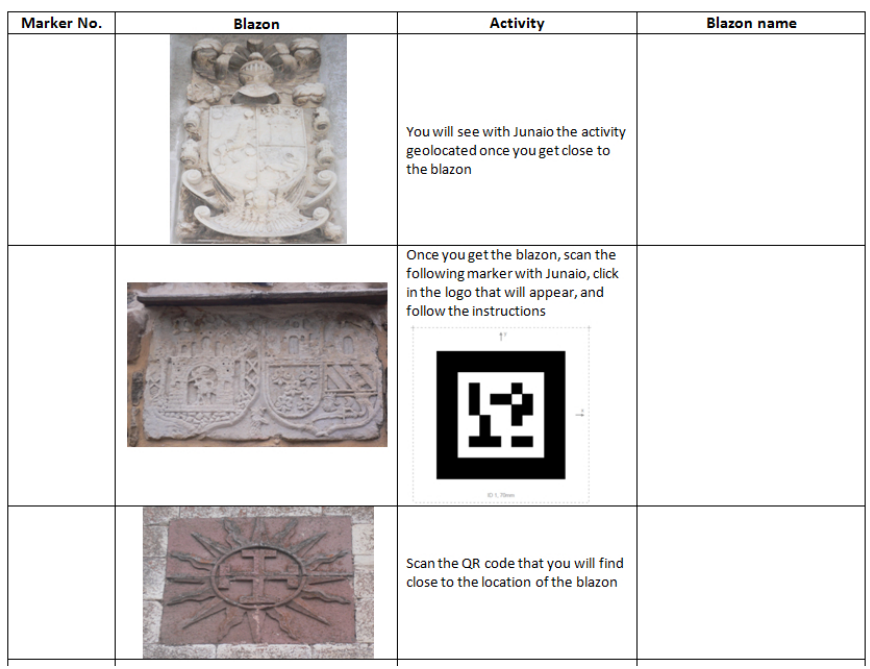

Figure 3. Partial view of the activity paper sheet (translated from the original in Spanish) with the three possible instructions to follow in a blazon

- An orienteering paper map of the village (see Fig. 2), indicating the start and finish points, and the location of the seven blazons.

- A paper sheet (see Fig. 3, Fig. 1 c, and Fig. 2) with the description of the learning situation and pictures of the seven blazons (without indicating their locations). In each blazon, the sheet included: an empty field to fill up with the name of the blazon; an empty field to indicate the marker number in the paper map corresponding to the blazon; instructions to perform the activity.

Fig. 3 shows a piece of the paper sheet (the same for all the groups), with the three possible procedures to follow when a blazon was located. The teachers decided to use the three types of AR (geolocation, QR code located close to a blazon, fiducial marker in the paper sheet) in order to illustrate to the students the different technological possibilities for augmenting physical spaces with virtual learning artifacts, as well as their advantages and disadvantages. The geolocated artifacts were configured to be visible with AR when the students were less than 20 meters away from the blazons.

In order to foster the autonomous work of the different groups, each group had to start the race in a different blazon, and there were only four groups conducting Game of Blazons simultaneously in each turn. Once a group found a blazon, they had to identify it in the paper sheet, indicating the corresponding marker number of the orienteering map, finding out the blazon name (usually interacting with locals) and performing the indicated activity. The activities that the students had to conduct at the blazons were of the following types:

- Answering a web-based quiz (created with Google Forms ${ }^{16}$ ) to reinforce and assess topics that had been lectured in the classroom, worked in groups (both

16. http://www.google.com/forms/about/. Last access December 2017. face-to-face and using Moodle), and/or experienced during the two days in the village (e.g., related to trekking, hiking, etc.).

- Conducting a geocaching activity. The identifier of a specific geocache (the geocaching "treasure") was given to the students in a Google Docs document, and they had to find the geocache using the geocaching app installed in the tablet (or alternatively, a geocaching app installed in their mobile phone).

- A name of something popular in the village was given in a Google Docs document, and the students had to interact with the village's inhabitants to find out who or what it was. The students had to write the answer in the Google Docs document.

The fiducial markers and geolocations pointed to different activities when accessed by different groups performing the race simultaneously. For example, in the same blazon, different groups accessed different quizzes, had to find different geocaches, or had to find out information regarding different characters. Once the activities in all the blazons were completed, or when the time limit expired, the students had to go to the finish point and draw the path they had followed, in the village map loaded in the drawing app of the tablet. Fig. 2 shows the orienteering map they used and snapshots of the learning situation, illustrating the different types of activities that the students carried out.

\subsection{Method}

We have followed the Evaluand-oriented Responsive Evaluation Model (EREM) [73] to design and carry out the evaluation. The EREM is an evaluation framework inspired in the responsive evaluation approach [74], and framed within the interpretive research paradigm [75]. This kind of evaluation does not pursue statistical significant results or generalizations, but it is aimed to the deep understanding of the phenomenon under study, in this case by means of the use of GLUEPS-AR by teachers in an authentic learning situation.

During the evaluation we used multiple data gathering techniques and sources (see Table 2), and we employed the NVivo ${ }^{17}$ software and spreadsheets for the analysis of the gathered data. In order to help illuminate the research question that we posed, we conducted a data reduction process [76] during the analysis (see Fig. 4). Thus, we defined an issue (how does GLUEPS-AR help the participant teachers create and enact Game of Blazons?) as the main conceptual organizer of the evaluation, dividing it into four topics to help understand the issue: the support provided for creating and enacting Game of Blazons (topic 1); the support provided for using different types of $A R$ and augmenting different types of spaces (topic 2); the support provided for integrating AR with other activities of the teachers' existing practice (topic 3); and the affordability for creating and enacting Game of Blazons (topic 4). In the same fashion, each topic was explored through different informative questions to help illuminate the topics.

We carried out different strategies to ensure the quality and rigor of the evaluation [77]. Some of such strategies

17. http://www.qsrinternational.com. Last access December 2017. 
Table 2

Summary of the data gathering techniques employed

\begin{tabular}{|c|c|}
\hline Technique & Description \\
\hline $\begin{array}{l}\text { Collection of } \\
\text { participant- } \\
\text { generated } \\
\text { artifacts } \\
\text { [Art] }\end{array}$ & $\begin{array}{l}\text { Collection of a diverse set of electronic artifacts } \\
\text { generated by the participant teachers. Types of data } \\
\text { collected include emails with teachers, learning } \\
\text { designs and products and educational materials. } \\
\text { Used for registering the learning design process, as } \\
\text { well as the use of the systems and tools by the } \\
\text { participants; being aware of the participants' } \\
\text { asynchronous activities; complementing the } \\
\text { observations with information of the generated } \\
\text { learning artifacts. }\end{array}$ \\
\hline $\begin{array}{l}\text { Screen } \\
\text { recording } \\
\text { [Screen] }\end{array}$ & $\begin{array}{l}\text { Recording, using specialized software, of the actions } \\
\text { performed in (screen recording) and out (video and } \\
\text { audio) the computer by the participants during } \\
\text { different evaluation happenings. Used for } \\
\text { understanding the design and deployment } \\
\text { processes, and measuring the amount of time that } \\
\text { these processes require. }\end{array}$ \\
\hline $\begin{array}{l}\text { Observation } \\
\text { [Obs] }\end{array}$ & $\begin{array}{l}\text { Naturalistic, semi-structured observations during } \\
\text { different evaluation happenings. The data collected } \\
\text { were audio/video recordings, pictures and } \\
\text { observation notes. Used for registering the actions, } \\
\text { impressions and other emergent issues of the } \\
\text { participants during different evaluation happenings. }\end{array}$ \\
\hline $\begin{array}{l}\text { Questionnaire } \\
\text { [Quest] }\end{array}$ & $\begin{array}{l}\text { Web-based exploratory questionnaire, designed in } \\
\text { an iterative review process by the research team. } \\
\text { Composed of open-ended and closed items (6-point } \\
\text { scale }[1=\text { strongly disagree, } 2=\text { disagree, } 3=\text { somewhat } \\
\text { disagree, } 4=\text { somewhat agree, } 5=\text { agree, } 6=\text { strongly } \\
\text { agree + Don't know /No answer). Used for } \\
\text { collecting the opinions of the participants about a } \\
\text { wide range of matters. }\end{array}$ \\
\hline $\begin{array}{l}\text { Interview } \\
\text { [Int] }\end{array}$ & $\begin{array}{l}\text { Semi-structured, face-to-face, one-to-one } \\
\text { conversation with the teachers (recorded and } \\
\text { transcribed). Used for capturing the opinions of the } \\
\text { teachers in depth, after an initial analysis of other } \\
\text { data sources (e.g., observation data, questionnaire } \\
\text { answers, etc.). }\end{array}$ \\
\hline
\end{tabular}

were triangulation of data sources, researchers and methods, as well as member checking, receiving feedback from the involved teachers about the data and interpretations.

Fig. 5 illustrates the evaluation process, which has been divided into happenings - evaluation events. The first happening (H1) consisted of preparation steps. It involved: a) two testing sessions, one with each teacher, where they tested GLUEPS-AR with the help of the research team; and b) a conceptual design phase, including a preliminary visit to the village. In a second happening $(\mathrm{H} 2)$, the teachers used the WebCollage authoring tool and GLUEPS-AR to author the learning situation and deploy it in the web and AR tools. During the session, the main teacher led the process, using WebCollage and GLUEPS-AR, while the assisting teacher helped him (e.g., creating the quizzes for the students). The third happening (H3) consisted in the enactment of Game of Blazons with 47 students in Cervera de Pisuerga. Finally, in the last happening we gathered the teachers' feedback (H4): we recorded an evaluation meeting conducted just after finishing Game of Blazons, in which the teachers reflected about the result of the learning situation, and later on, feedback from them was retrieved using a web-based questionnaire followed by interviews.

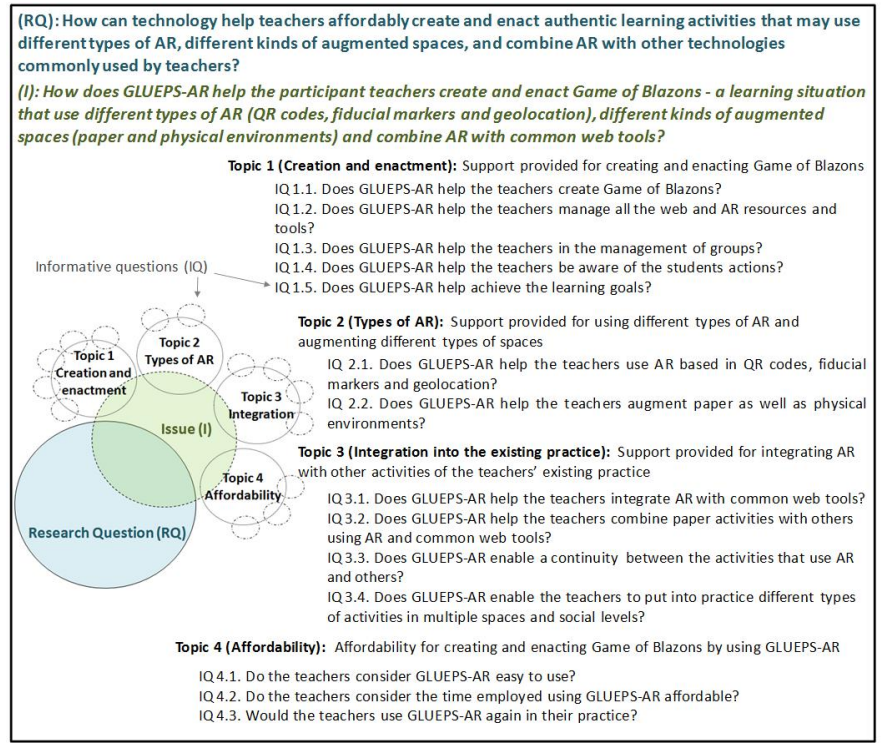

Figure 4. Data reduction showing research question $(R Q)$, issue (I), topics and informative questions (IQ)

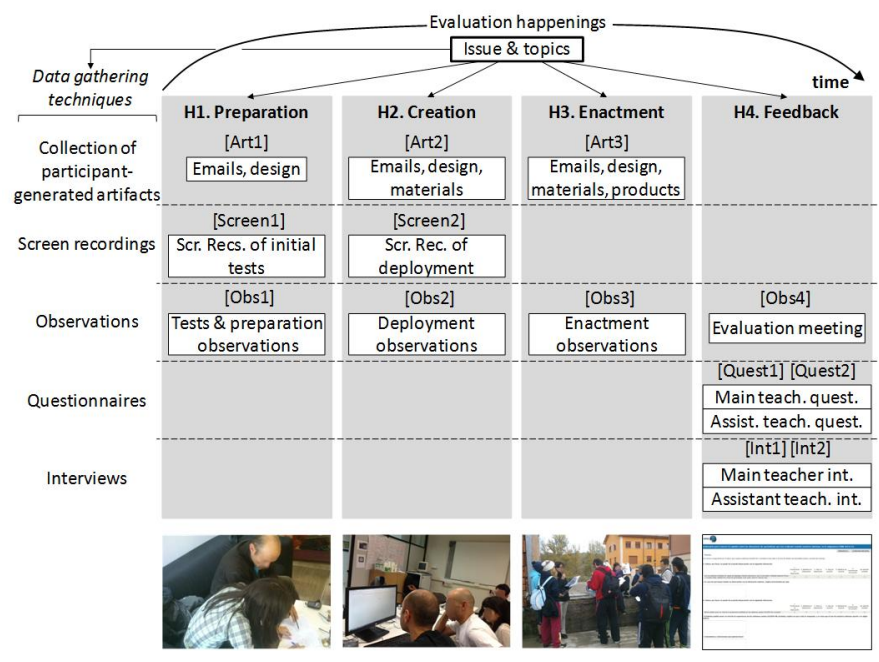

Figure 5. Evaluation happenings and data gathering techniques used during the evaluation, as well as snapshots of the happenings

\subsection{Results}

This section describes the main findings obtained during the evaluation process, structured using the topics of the data reduction schema (see Fig. 4). Each finding is supported with different excerpts of evidence gathered in the evaluation. For a better readability, only a selection of excerpts is presented, which is included in the Appendix. Table 3 summarizes the main results obtained in the evaluation, indicating, using the same labels as in Fig. 5, the data sources that support the results. This table exemplifies the triangulation process followed in the study.

\subsubsection{Topic 1. Creation and enactment}

The evidence gathered during the evaluation indicates that GLUEPS-AR helped the teachers create and enact the Game of Blazons learning situation, as well as aided in 
Table 3

Main results of the evaluation process

\begin{tabular}{|l|l|l|}
\hline Topic & Results & $\begin{array}{l}\text { Supporting } \\
\text { Data }\end{array}$ \\
\hline $\begin{array}{l}\text { 1. Creation } \\
\text { and } \\
\text { enactment }\end{array}$ & $\begin{array}{l}\text { GLUEPS-AR helped the teachers create } \\
\text { and enact the Game of Blazons learning } \\
\text { situation, as well as aided in engaging } \\
\text { the students and achieving the learning } \\
\text { goals. GLUEPS-AR monitoring features } \\
\text { could be enhanced by adding a post-hoc } \\
\text { register of students actions in a map. }\end{array}$ & $\begin{array}{l}\text { Art1-3, } \\
\text { Int1-2, } \\
\text { Obs1-4, } \\
\text { Quest1-2, } \\
\text { Screen1-2 }\end{array}$ \\
\hline $\begin{array}{l}\text { 2. Types of } \\
\text { AR }\end{array}$ & $\begin{array}{l}\text { GLUEPS-AR helped the teachers use } \\
\text { different types of AR (geolocation, } \\
\text { fiducial markers and QR codes) and } \\
\text { augment different types of spaces } \\
\text { (physical environment and paper). Also, }\end{array}$ & $\begin{array}{l}\text { Art1-3, Int1, } \\
\text { Obs1-4, } \\
\text { Quest1-2, } \\
\text { Screen2 }\end{array}$ \\
$\begin{array}{l}\text { GLUEPS-AR should support different } \\
\text { types of geographical coordinates. }\end{array}$ & $\begin{array}{l}\text { GLUEPS-AR helped the teachers } \\
\text { integrate the use of AR with other } \\
\text { activities based on paper and pencil, } \\
\text { common web tools and mobile apps, } \\
\text { achieving continuity between the } \\
\text { different activities and tools. Also, the } \\
\text { teachers would need more experience } \\
\text { integrationg GLUEPS-AR to create more } \\
\text { existing } \\
\text { practice } \\
\text { complex and significant pedagogical } \\
\text { scenarios. }\end{array}$ & $\begin{array}{l}\text { Art1-3, } \\
\text { Int1-2, } \\
\text { Obs1-4, } \\
\text { Quest1-2, } \\
\text { Screen1-2 }\end{array}$ \\
\hline $\begin{array}{l}\text { 4. Afford- } \\
\text { ability }\end{array}$ & $\begin{array}{l}\text { The use of GLUEPS-AR was affordable } \\
\text { for the teachers and they would use it in } \\
\text { their educational practice. However, it } \\
\text { required an initial training and some } \\
\text { practice. Also the use of an additional } \\
\text { authoring tool added extra complexity } \\
\text { and made the process long. }\end{array}$ & $\begin{array}{l}\text { Art1, Int1-2, } \\
\text { Obs1-4, } \\
\text { Quest1-2, } \\
\text { Screen1-2 }\end{array}$ \\
\hline
\end{tabular}

engaging the students and achieving the learning goals. GLUEPS-AR helped the teachers create Game of Blazons by enabling them to use an existing learning design authoring tool (WebCollage) and to deploy the created design in common mobile AR clients (Junaio and any QR code reader), a VLE (Moodle) and Web 2.0 tools (Google Docs and Google Forms) (see, e.g., Table 4, as well as [Quest1-2] and [Screen2] in Table A1 of the Appendix). The teachers' process of creating and conceptualizing the design was iterative, and such design was not completely finished until the deployment session in which the technological resources were set up (two days before the enactment) (see, e.g., [Art1] in Table A1 of the Appendix). GLUEPS-AR also helped the teachers manage the different learning tools and artifacts (see Table 4) by automating the creation of tool instances and by organizing the resources in a control panel: the GLUEPS-AR user interface (see, e.g., [Int2] and [Quest1-2] $]_{B}$ in Table A1 of the Appendix). With respect to this aspect, a negative point was that the GLUEPS-AR prototype employed by the teachers did not implement a Google Forms adapter, which implied that quizzes had to be created manually, and included in GLUEPS-AR using their URLs. Regarding the management of groups, GLUEPSAR helped use collaborative learning, enabling the teachers to configure groups of students, and allowing different groups to access different artifacts in the same marker or geolocation (see, e.g., [Int2] and [Obs4] $]_{\mathrm{A}}$ in Table A1 of the Appendix). Another interesting aspect was that despite groups mostly used the tablets provided by the evaluation
Table 4

Activities and artifacts created using GLUEPS-AR in Game of Blazons, indicating in each activity the number of groups and artifacts, the tool type, the AR type and the kind of augmented space

\begin{tabular}{|c|c|c|c|c|c|}
\hline Activity & \begin{tabular}{l|} 
No. \\
groups
\end{tabular} & $\begin{array}{l}\text { No. } \\
\text { web } \\
\text { arti- } \\
\text { facts }\end{array}$ & $\begin{array}{l}\text { Web } \\
\text { tool }\end{array}$ & $\begin{array}{l}\text { AR type for } \\
\text { delivery to } \\
\text { students }\end{array}$ & $\begin{array}{l}\text { Augmented } \\
\text { space }\end{array}$ \\
\hline $\begin{array}{l}\text { 1. Group } \\
\text { management }\end{array}$ & 16 & 2 & $\begin{array}{l}\text { Google } \\
\text { Forms }\end{array}$ & $\begin{array}{l}\text { Fiducial } \\
\text { marker }\end{array}$ & Paper \\
\hline $\begin{array}{l}\text { 2. Ethnographic } \\
\text { inquiry }\end{array}$ & 16 & 16 & $\begin{array}{l}\text { Google } \\
\text { Docs }\end{array}$ & Geolocation & $\begin{array}{l}\text { Physical en- } \\
\text { vironment }\end{array}$ \\
\hline 3. The backpack & 16 & 2 & $\begin{array}{l}\text { Google } \\
\text { Forms }\end{array}$ & $\begin{array}{l}\text { Fiducial } \\
\text { marker }\end{array}$ & Paper \\
\hline $\begin{array}{l}\text { 4. Calculate } \\
\text { distance }\end{array}$ & 16 & 1 & $\begin{array}{l}\text { Google } \\
\text { Forms }\end{array}$ & QR code & $\begin{array}{l}\text { Physical en- } \\
\text { vironment }\end{array}$ \\
\hline 5. Geocaching & 16 & 3 & $\begin{array}{l}\text { Google } \\
\text { Docs }\end{array}$ & $\begin{array}{l}\text { Fiducial } \\
\text { marker }\end{array}$ & Paper \\
\hline $\begin{array}{l}\text { 6. Enlivening } \\
\text { paths }\end{array}$ & 16 & 1 & $\begin{array}{l}\text { Google } \\
\text { Forms }\end{array}$ & QR code & $\begin{array}{l}\text { Physical en- } \\
\text { vironment }\end{array}$ \\
\hline $\begin{array}{l}\text { 7. Paths } \\
\text { network }\end{array}$ & 16 & 2 & $\begin{array}{l}\text { Google } \\
\text { Forms }\end{array}$ & Geolocation & $\begin{array}{l}\text { Physical en- } \\
\text { vironment }\end{array}$ \\
\hline TOTAL & 16 & 27 & $\begin{array}{l}2 \text { web } \\
\text { tools }\end{array}$ & 3 AR types & $\begin{array}{l}2 \\
\text { augmented } \\
\text { spaces }\end{array}$ \\
\hline
\end{tabular}

team (which favored the success of the learning situation by avoiding burdening teachers with the multiple potential issues that could arise in the students' own devices), several students used also their mobile phones. Such use of their own device was promoted by the teachers in order to help transfer the students' learning to other formal and informal contexts. The use of tablets also restricted the number of students to three per group, although such number adjusted well to the teachers' aims (see, e.g., [Obs4 $]_{\mathrm{A}}$ in Table A1 of the Appendix). GLUEPS-AR also allowed the teachers to monitor with Junaio the location of the students during the enactment (see in Fig. 6 a screenshot taken during the enactment), but the teachers did not have enough time to use such feature continuously during the learning situation, and they just used it sporadically with the mobile device of a member of the evaluation team (see, e.g., [Obs3] and $[\mathrm{Obs} 4]_{\mathrm{B}}$ in Table A1 of the Appendix). The evaluation showed that such awareness feature could be enhanced with a map view to be used after the end of the activities, including the registry of the work performed by the students, indicating times and locations. GLUESP-AR already stored such information, but it was not provided to the teachers nor included in the user interface. The teachers recognized that GLUEPS-AR helped achieve the learning goals, while engaging and motivating the students (see, e.g., [Quest1-2] $]_{C}$ and [Obs4 $]_{C}$ in Table A1 of the Appendix). Table A1 of the Appendix shows some selected excerpts of evidence that illustrate these findings.

\subsubsection{Topic 2. Types of $A R$}

Regarding the types of AR supported, the main teacher wanted to use all the possible options of AR, in order to teach the students the different technological possibilities to augment physical spaces (see, e.g., [Screen2] $]_{A, B}$ in Table A2 of the Appendix). The evaluation suggests that GLUEPSAR helped the teachers use different types of AR and augment different types of spaces (see Table 4). GLUEPSAR enabled the teachers to include in their design AR based 
on QR codes, fiducial markers and geolocation. GLUEPS-AR also allowed the teachers and the students to use such types of AR during the enactment by means of common mobile AR clients such as Junaio and Neoreader (see, e.g., [Obs 3$]_{\mathrm{A}}$, [Quest1-2] and [Screen2] $]_{B}$ in Table A2 of the Appendix). In addition, GLUEPS-AR helped the teachers augment physical environments and paper. Thus, a paper sheet was an instrument that enabled traditional work (reading, writing, sharing it, etc.), while it also augmented digitally the stone blazons (see, e.g., [Obs3 $]_{B}$ and [Screen2 $]_{C}$ in Table A2 of the Appendix). In order to facilitate the handling of markers (e.g., cut them out or copy and paste them in documents), the GLUEPS-AR user interface provided a list of the markers used in the learning situation ( $\mathrm{QR}$ codes and fiducial markers) (see, e.g., [Screen2] $]_{D}$ in Table A2 of the Appendix). During Game of Blazons the different types of AR showed different affordances. The use of geolocation and fiducial markers enabled the teachers to provide different learning artifacts to different groups of the students in the same position (e.g., a geolocation or a marker). Also, the predefinition by the teachers of the geolocation of learning artifacts, and the inclusion of fiducial markers in the paper sheet, saved time in the preparation of the learning situation in the village. This way, only two $Q R$ codes had to be placed and removed in situ (which, in addition, had to stay 5 hours in such locations, which was a risk of losing them). On the other hand, placing the QR codes in situ allowed a higher precision for locating them, which was important in Game of Blazons for training orienteering skills (a geolocated artifact was configured by the teacher to be visible using AR when the students were less than 20 meters away from the blazon, while the students had to find the exact location of the QR codes). Also, including fiducial markers in the paper sheet enabled the teachers to reuse the paper template by giving a copy of the same paper sheet to each group of students. Moreover, the sheet could be reused in subsequent years, since GLUEPS-AR allows the teachers to easily change in subsequent editions of the course the virtual objects associated with the fiducial markers. Finally, the usage of different types of AR facilitated the remote creation of the learning situation, being only necessary to know

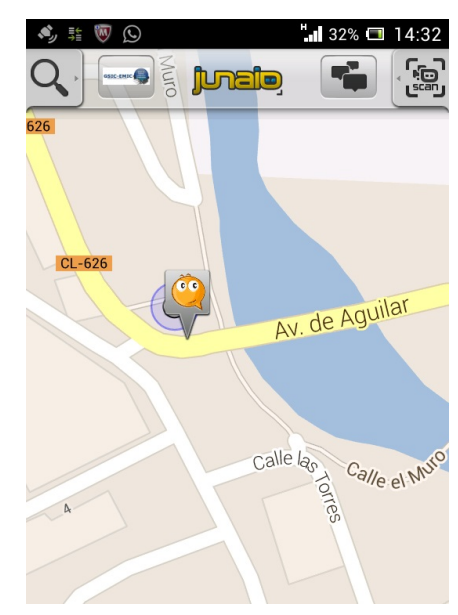

Figure 6. Junaio map view showing the runtime location of a group of students during the enactment of Game of Blazons [Obs3] beforehand the exact position of some of the blazons (the geolocated ones), and enabling last-time remote decisions (see, e.g., [Art1], [Obs2] and [Screen2] $]_{B}$ in Table A2 of the Appendix).

A potential improvement to GLUEPS-AR was identified during the evaluation, due to a problem in the format of the geographical coordinates. While GLUEPS-AR used decimal coordinates (the Google Maps format), the main teacher's GPS used UTM coordinates. This generated difficulties and delays in the deployment process for converting the geographical coordinates that the teacher gathered in situ when preparing the learning situation to the GLUEPS-AR format. Table A2 of the Appendix shows a selection of excerpts of evidence that illustrates the aforementioned findings.

\subsubsection{Topic 3. Integration into the existing practice}

In this topic we explored how AR is integrated with other activities of the teachers' practice. The evaluation showed that GLUEPS-AR helped the teachers integrate the use of AR with other activities based on paper and pencil, common web tools and mobile apps, achieving continuity between the different activities and tools. GLUEPS-AR enabled the teachers to associate different Web 2.0 tools (Google Docs and Google Forms) with different AR types (see Table 4). This association enabled the access, using AR, to Web 2.0 tool instances positioned in geolocations and QR codes placed close to stone blazons, which allowed teachers to know that the students had reached the blazons, and to enrich the blazons with learning contents (important aspects in orienteering activities). GLUEPS-AR also enabled the access to Web 2.0 tool instances positioned in fiducial markers included in the activity paper sheet (see, e.g., [Obs2], [Obs3 $]_{\mathrm{A}, \mathrm{B}}$ in Table A3 of the Appendix). Thus, some activities conducted with the paper map and the paper sheet (orienteering, identifying blazons), were combined with other activities carried out using Web 2.0 tools and mobile apps (geocaching, drawing the followed track, ethnographic inquiry, and quizzes related to topics lectured in the classroom and experienced during the two days in the village) (see, e.g., $[\mathrm{Obs} 3]_{\mathrm{A}, \mathrm{B}}$ in Table $\mathrm{A} 3$ of the Appendix). The teachers highlighted the GLUEPS-AR aid to the achievement of continuity between these activities (see, e.g., [Quest1-2] $]_{\mathrm{A}}$ in Table A3 of the Appendix). The use of AR was an important factor to attain the connection of the different activities and tools. GLUEPS-AR also enabled the teachers to integrate the AR activities with a VLE such as Moodle (see, e.g., [Int2] and [Screen1] in Table A3 of the Appendix). The paper sheet acted as a script for the students, guiding them, together with the orienteering map, over the different locations and activities (see, e.g., [Obs3 $]_{C}$ in Table A3 of the Appendix). Apart from the activities carried out in Game of Blazons, the teachers recognized that GLUEPS-AR may enable the carrying out of several other types of activities in multiple spaces and social levels (individual, group, class), as well as using different pedagogical methodologies (see, e.g., [Int2] and [Quest1$2]_{B, C, D, E}$ in Table A3 of the Appendix). However, although they thought that GLUEPS-AR could afford such range of applicability, they acknowledged that they would need to conduct more learning situations to confirm it (see, e.g., $[\mathrm{Obs} 4]_{\mathrm{A}}$ in Table A3 of the Appendix). During the study, 
the teachers showed a major concern in being able to take advantage of the possibilities of technology for enriching learning in ULEs, without losing the essence of conducting learning activities in nature. All in all, the teachers were happy with the result of Game of Blazons and its connection of different pedagogical dimensions, and they perceived that the scenario would be easily transferable to other contexts (see, e.g., $[\mathrm{Obs} 4]_{\mathrm{B}}$ in Table A3 of the Appendix). They also recognized that the technological setting deployed with GLUEPS-AR fitted very well with the contents of the course. However, they would need more time to reflect about the potential of GLUEPS-AR to create more complex, adjusted and significant pedagogical scenarios, because the rhythm of the course was very fast and they were very short of time to prepare Game of Blazons and reflect about it (see, e.g., [Int1] in Table A3 of the Appendix). Table A3 of the Appendix shows a selection of excerpts that illustrate these findings.

\subsubsection{Topic 4. Affordability}

In this topic, we explored the affordability for the teachers to put into practice Game of Blazons using GLUEPS-AR. The evaluation indicates that the teachers did not consider GLUEPS-AR easy to use. However, they assessed its use as affordable with an initial training and a little of practice (see, e.g., $[\text { Int1 }]_{\mathrm{A}},[\text { Int2 }]_{\mathrm{A}},[\text { Quest1-2 }]_{\mathrm{A}},[$ Obs1] and [Screen1] in Table A4 of the Appendix). In addition to this initial training, the teachers considered that it would be necessary to raise awareness among some teachers about the possibilities of the tool and the benefits that it could provide in the learning process of their students, to convince them to use it (see, e.g., [Int1 $]_{\mathrm{A}, \mathrm{B}}$ and [Int2 $]_{\mathrm{B}}$ in Table A4 of the Appendix). Also, the additional use of an authoring tool (WebCollage) introduced extra complexity (see, e.g., [Int2] $]_{C}$ in Table A4 of the Appendix) and caused some problems (e.g., incoherences between the learning situation in the authoring tool and in GLUEPS-AR, due to errors or modifications of the design). The teachers considered the time required to deploy Game of Blazons using GLUEPSAR (see Table 5) long. However, they judged such time as affordable and they acknowledged that it would be reduced with practice (see, e.g., [Quest1-2 $]_{\mathrm{B}}$ in Table A4 of the Appendix). This time could be also severely reduced by automating multiple repetitive operations that had to be performed in the GLUEPS-AR user interface (see, e.g., [Screen2] in Table A4 of the Appendix). All in all, the teachers recognized that they would use again GLUEPSAR in their practice, without saturating the course with technological activities (see, e.g., [Quest1-2]C in Table A4 of the Appendix).

During the enactment of Game of Blazons, we had several minor problems related to the technology that were easily solved with the help of the evaluation team or the assistant teacher (sometimes checking with an evaluator by phone). Some of those problems were: tablets not configured to allow Junaio access the geolocation of the tablet; some errors in Junaio that required to restart the app; a QR code placed in a curved surface that made difficult the scanning; some initial difficulties for the students to choose the correct application (Junaio/neoreader) or the correct mode inside Junaio (there were different modes to see marker based
Table 5

Time devoted by the teachers in the different deployments involved in the study

\begin{tabular}{|c|c|c|c|c|}
\hline \multirow[b]{2}{*}{ Deployment } & \multirow[b]{2}{*}{ Actor } & \multicolumn{3}{|l|}{ Time } \\
\hline & & WebCollage & GLUEPS-AR & Total \\
\hline Test design 1 & \begin{tabular}{|l} 
Main \\
teacher
\end{tabular} & & $15 \mathrm{~min}$ & $15 \mathrm{~min}$ \\
\hline Test design 2 & $\begin{array}{l}\text { Assistant } \\
\text { teacher }\end{array}$ & $23 \mathrm{~min}$ & $10 \mathrm{~min}$ & $33 \mathrm{~min}$ \\
\hline $\begin{array}{l}\text { Game of } \\
\text { Blazons }\end{array}$ & $\begin{array}{l}\text { Main } \\
\text { teacher }\end{array}$ & $1 \mathrm{~h} 30 \mathrm{~min}$ & $2 \mathrm{~h} 48 \min ^{a}$ & $3 \mathrm{~h} 18 \min ^{a}$ \\
\hline
\end{tabular}

a. Including $10 \mathrm{~min}$ of repetitive operations performed by a member of the evaluation team

and geolocation based AR); a Google Docs requirement for mobile devices to authenticate to access public shared documents; and the necessity of loading the tablets' batteries during the lunch time (see, e.g., [Obs3] in Table A4 of the Appendix). Table A4 of the Appendix shows some selected excerpts of evidence gathered during the evaluation, which can illustrate the mentioned findings.

\section{Conclusions}

Game of Blazons is a learning situation that was carried out by two teachers of a course on Physical Education in the Natural Environment for pre-service teachers. The situation involved the use of different types of AR: QR codes and geolocation, which augmented stone blazons chiseled in the houses of a medieval Spanish village, as well as fiducial markers, which augmented a paper sheet used as a script of the learning situation. Game of Blazons included the use of web tools, mobile apps and paper and pencil. The evidence gathered during the evaluation shows that GLUEPS-AR provided an affordable support to the teachers for creating and enacting Game of Blazons. The evidence also suggests that GLUEPS-AR could help teachers put into practice other different learning situations that use multiple types of $A R$, augment physical environments or paper, and integrate AR with other tools commonly used in education, such as VLEs and Web 2.0 tools. Thus, the GLUEPS-AR approach can be a more general alternative to other works for using AR in education that focus on specific technologies, activities or pedagogies. On the other hand, although such more general approach can extend the possible range of applicability, it could also be less suitable for specific scenarios or purposes, where an ad-hoc solution could be more appropriate. It is also worth highlighting that the research presented in this paper does not aim to improve the current state of the art of $\mathrm{AR}$, but it is focused on helping in the application of AR in education. Research about AR technology is an interesting avenue for further research.

With respect to the use of authoring tools, the evaluation showed that although the use of WebCollage and GLUEPSAR enabled the teachers to create Game of Blazons, those two tools added a significant complexity and effort to the design process. In some cases, the complexity of the learning situation might be worth the effort (e.g., those using collaborative patterns). But in other cases, this additional effort could prevent teachers from using GLUEPS-AR (or 
at least, from using it repetitively). That could be the case of teachers with little time available, or that plan to design and set up the technological environment shortly before the actual enactment. In this line, we are already exploring alternatives for enabling teachers to create, directly from their usual learning environments (and thus avoiding the use of additional authoring tools), not very complex learning situations that may include AR and web tools [78]. Also, further research is necessary to implement in GLUEPS-AR means for helping the teachers select the more suitable AR tools for their educational goals.

During the evaluation, several minor technological problems arose, that were solved with the help of a member of the evaluation team. However, in the context in which the learning situation was carried out (an outdoor scenario covering a whole village, with 47 students working in groups), such problems could have overloaded a single teacher. Thus, it is important for the teachers to anticipate the maximum number of possible issues (e.g., by testing part of the scenario in a nearby context), and explain the students how to detect and solve the known issues. Communication with students is also important in this kind of scenarios. We used mobile devices and walkie-talkies, but the means for communicating could also be a part of the learning environment and it is a matter for further research. In addition, the teacher should be ready for switching to backup alternatives in the design, and even to put into practice a backup plan if technology would not be available. This is especially important in outdoor scenarios that can be affected by issues related to the weather, the battery of the devices, the Internet connection, the mobile coverage, etc. During the enactment of Game of Blazons, the teachers did not need to adapt the design at runtime, but it is a feature that we consider important especially in these kind of scenarios, and we plan to study it in the future.

We should also further explore how to improve the monitoring features of GLUEPS-AR, since during the evaluation we verified that teachers need simple and efficient instruments to be able to control and be aware of the students' actions. The GLUEPS-AR awareness features should be enhanced to enable a simpler use by teachers with very little time available during the enactment. Also, the positive feedback received by the teachers to the use of augmented reality for providing runtime user awareness encourages us to continue in this line of research [79], without forgetting about the ethical and privacy issues that might derive from such monitoring [80].

Another issue that needs further research is the necessity of allowing the students to participate in the creation of the learning situations, in order to enable them not only to be passive receptors of contents, but also creators, something especially important in this case in the training of the students as future teachers. However, GLUEPS-AR, like other approaches based on the use of authoring tools, forces the teacher to predefine all the tools and artifacts to be used by the students during the enactment. We are also exploring how GLUEPS-AR could implement features to improve the flexibility offered to the students in this aspect [81].

We plan to study the use of GLUEPS-AR in other contexts, and with other teachers, in order to investigate in depth the GLUEPS-AR range of applicability and the support provided for different kind of scenarios. In this line, a possible future work is the comparison of the support provided by different systems to the creation and enactment of a range of non-trivial learning situations with a clear need for the integration of AR-based activities, as well as the comparison of the educational results using and not using GLUEPS-AR. In addition, further research would be necessary to explore in detail the GLUEPS-AR support to different pedagogical approaches. A particular pedagogy which we are already investigating is game-based learning. Although the teachers considered Game of Blazons as a kind of educational game, we would like to explore how GLUEPS-AR supports game-based learning, and how it could enable teachers a gamification of their usual learning situations that involve multiple physical and virtual spaces [82]. We also plan to study the learning effects of the use of GLUEPS-AR from the point of view of the students, an important aspect that we have not dealt with in this study.

\section{ACKNOWLEDGEMENTS}

This research has been partially supported by the Spanish Ministry of Economy and Competitiveness (projects TIN2011-28308-C03-02 and TIN2014-53199-C3-2-R) and the Regional Government of Castilla y León (projects VA277U14 and VA082U16). The authors thank the rest of the GSIC/EMIC research team for their ideas and support.

\section{REFERENCES}

[1] R. Azuma, Y. Baillot, R. Behringer, S. Feiner, S. Julier, and B. MacIntyre, "Recent advances in augmented reality," IEEE Computer Graphics and Applications, vol. 21, no. 6, pp. 34-47, 2001.

[2] S. Harrison and P. Dourish, "Re-place-ing space: the roles of place and space in collaborative systems," in ACM Conference on Computer Supported Cooperative Work, ser. CSCW '96. Boston, Massachusetts, USA: ACM, November 1996, pp. 67-76.

[3] L. Ciolfi, "Understanding spaces as places: Extending interaction design paradigms," Cognition, Technology and Work, vol. 6, no. 1 pp. 37-40, Feb. 2004.

[4] M. Dunleavy, C. Dede, and R. Mitchell, "Affordances and limitations of immersive participatory augmented reality simulations for teaching and learning," Journal of Science Education and Technology, vol. 18, no. 1, pp. 7-22, 2009.

[5] K. Sheehy, R. Ferguson, and G. Clough, Augmented Education: Bringing Real and Virtual Learning Together (Digital Education and Learning). New York, NY, USA: Palgrave Macmillan, 2014.

[6] H.-K. Wu, S. W.-Y. Lee, H.-Y. Chang, and J.-C. Liang, "Current status, opportunities and challenges of augmented reality in education," Computers \& Education, vol. 62, pp. 41-49, 2013.

[7] G. Papagiannakis, G. Singh, and N. Magnenat-Thalmann, "A survey of mobile and wireless technologies for augmented reality systems," Computer Animation and Virtual Worlds, vol. 19, no. 1, pp. 3-22, February 2008.

[8] L. P. Prieto, M. H. Dlab, I. Gutiérrez, M. Abdulwahed, and W. Balid, "Orchestrating technology enhanced learning: A literature review and a conceptual framework," International Journal of Technology Enhanced Learning, vol. 3, no. 6, pp. 583-598, 2011.

[9] P. Dillenbourg and P. Jermann, "Technology for classroom orchestration," in New Science of Learning Cognition Computers and Collaboration in Education, M. S. Khine and I. M. Saleh, Eds. New York, NY: Springer New York, 2010, pp. 1-20.

[10] E. Klopfer, J. Sheldon, J. Perry, L. Rosenheck, K. Squire, J. Mathews, R. B. Shapiro, B. Coulter, and M. Dunleavy, "Augmented reality games: Place-based digital learning," in 9th International ComputerSupported Collaborative Learning Conference, Hong Kong, China, July 2011, pp. 1023-1028. 
[11] K.-H. Cheng and C.-C. Tsai, "Affordances of augmented reality in science learning: Suggestions for future research," Journal of Science Education and Technology, vol. 22, no. 4, pp. 449-462, 2013.

[12] L. P. Prieto, Y. Wen, D. Caballero, and P. Dillenbourg, "Review of augmented paper systems in education: An orchestration perspective," Journal of Educational Technology E Society, vol. 17, no. 4, pp. 169-185, 2014.

[13] S. Cuendet, Q. Bonnard, S. Do-Lenh, and P. Dillenbourg, "Designing augmented reality for the classroom," Computers $\mathcal{E}$ Education, vol. 68, pp. 557-569, 2013.

[14] C. Keller, "Virtual learning environments: Three implementation perspectives," Learning, Media and Technology, vol. 30, no. 3, pp. 299-311, 2005.

[15] G. Conole and P. Alevizou, "A literature review of the use of web 2.0 tools in higher education," The Open University, A report commissioned by the Higher Education Academy, 2010. [Online]. Available: https://www.heacademy.ac.uk/resource/ literature-review-use-web-20-tools-higher-education

[16] J. Niramitranon, M. Sharples, C. Greenhalgh, and C.-P. Lin, "Orchestrating learning in a one-to-one technology classroom," in 6th IEEE International Conference on Wireless, Mobile and Ubiquitous Technologies in Education (WMUTE), Kaohsiung, Taiwan, April 2010, pp. 96-103.

[17] J. A. Muñoz-Cristóbal, L. P. Prieto, J. I. Asensio-Pérez, A. Martínez-Monés, I. M. Jorrín-Abellán, and Y. Dimitriadis, "Deploying learning designs across physical and web spaces: Making pervasive learning affordable for teachers," Pervasive and Mobile Computing, vol. 14, pp. 31-46, 2014.

[18] J. A. Muñoz-Cristóbal, I. M. Jorrín-Abellán, J. I. Asensio-Pérez, A. Martínez-Monés, L. P. Prieto, and Y. Dimitriadis, "Supporting teacher orchestration in ubiquitous learning environments: A study in primary education," IEEE Transactions on Learning Technologies, vol. 8, no. 1, pp. 83-97, 2015.

[19] H. E. Pence, "Smartphones, smart objects, and augmented reality," The Reference Librarian, vol. 52, no. 1-2, pp. 136-145, 2010.

[20] D. W. F. van Krevelen and R. Poelman, "A survey of augmented reality technologies, applications and limitations," The International Journal of Virtual Reality, vol. 9, no. 2, pp. 1-20, Jun. 2010.

[21] P. Santos, M. Pérez-Sanagustín, D. Hernández-Leo, and J. Blat., "Space-aware design factors for located learning activities supported with smart phones," in IEEE 10th International Symposium on Parallel and Distributed Processing with Applications (ISPA), Madrid, Spain, July 2012, pp. 792-798.

[22] K. Facer, R. Joiner, D. Stanton, J. Reid, R. Hull, and D. Kirks, "Savannah: Mobile gaming and learning?" Journal of Computer Assisted Learning, vol. 20, no. 6, pp. 399-409, 2004.

[23] C. L. Holden and J. M. Sykes, "Leveraging mobile games for place-based language learning," International Journal of Game-Based Learning (IJGBL), vol. 1, no. 2, pp. 1-18, 2011.

[24] E. Klopfer, Augmented Learning: Research and Design of Mobile Educational Games. Cambridge, MA: The MIT Press, 2008.

[25] E. Klopfer and K. Squire, "Environmental detectives - the development of an augmented reality platform for environmental simulations," Educational Technology Research and Development, vol. 56, no. 2, pp. 203-228, 2008.

[26] K. D. Squire and M. Jan, "Mad city mystery: Developing scientific argumentation skills with a place-based augmented reality game on handheld computers," Journal of Science Education and Technology, vol. 16, no. 1, pp. 5-29, 2007.

[27] S. Ternier, R. Klemke, M. Kalz, P. van Ulzen, and M. Specht, "ARLearn: Augmented reality meets augmented virtuality," Journal of Universal Computer Science, Special Issue on Technology for learning across physical and virtual spaces, vol. 18, no. 15, pp. 2143-2164, 2012.

[28] J. Cook, "User generated contexts across spaces - design research perspectives," in Across Spaces Workshop, European Conference-Technology Enhanced Learning, Palermo, Italy, September 2011.

[29] A. M. Kamarainen, S. Metcalf, T. Grotzer, A. Browne, D. Mazzuca, M. S. Tutwiler, and C. Dede, "EcoMOBILE: Integrating augmented reality and probeware with environmental education field trips," Computers $\mathcal{E}$ Education, vol. 68, pp. 545-556, 2013.

[30] G. Robles, J. Gonzales-Barahona, and J. Fernandez-Gonzales, "Implementing gymkhanas with android smartphones: A multimedia m-learning game," in Global Engineering Education
Conference (EDUCON), 2011 IEEE, Amman, Jordan, April 2011, pp. $960-968$.

[31] P. Santos, M. Pérez-Sanagustín, D. Hernández-Leo, and J. Blat, "QuesTInSitu: From tests to routes for assessment in situ activities," Computers $\mathcal{E}$ Education, vol. 57, no. 4, pp. 2517-2534, 2011.

[32] M. Billinghurst and A. Duenser, "Augmented reality in the classroom," Computer, vol. 45, no. 7, pp. 56-73, 2012.

[33] E. FitzGerald, "Situ8: Browsing and capturing geolocated usercreated content," in CALRG Annual Conference 2013, Milton Keynes, UK, June 2013.

[34] M. Blanca Ibáñez, D. Maroto, J. J. García Rueda, D. Leony, and C. Delgado Kloos, "Architecture for collaborative learning activities in hybrid learning environments," Journal of Universal Computer Science, vol. 18, no. 15, pp. 2187-2202, 2012.

[35] H. Kato and M. Billinghurst, "Marker tracking and HMD calibration for a video-based augmented reality conferencing system," in 2nd IEEE and ACM International Workshop on Augmented Reality, 1999. (IWAR '99), San Francisco, CA, USA, 1999, pp. 85 -94.

[36] D. Spikol and J. Eliasson, "Lessons from designing geometry learning activities that combine mobile and 3D tools," in 6th IEEE International Conference on Wireless, Mobile and Ubiquitous Technologies in Education (WMUTE), 2010, Kaohsiung, Taiwan, April 2010, pp. 137-141.

[37] D. Pérez-López, M. Contero, and M. Alcañiz, "Collaborative development of an augmented reality application for digestive and circulatory systems teaching," in IEEE 10th International Conference on Advanced Learning Technologies (ICALT), 2010, Sousse, Tunisia, July 2010, pp. $173-175$.

[38] Á. Di Serio, M. B. Ibáñez, and C. Delgado Kloos, "Impact of an augmented reality system on students' motivation for a visual art course," Computers $\mathcal{E}$ Education, vol. 68, pp. 586-596, 2013.

[39] A. Echeverría, M. Améstica, F. Gil, M. Nussbaum, E. Barrios, and S. Leclerc, "Exploring different technological platforms for supporting co-located collaborative games in the classroom," Computers in Human Behavior, vol. 28, no. 4, pp. 1170-1177, 2012.

[40] N. Enyedy, J. A. Danish, G. Delacruz, M. Kumar, and S. Gentile, "Play and augmented reality in learning physics: The spases project," in Connecting Computer-Supported Collaborative Learning to Policy and Practice: CSCL2011 Conference Proceedings. Volume ILong Papers, July 2011, pp. 216-223.

[41] L. Kerawalla, R. Luckin, S. Seljeflot, and A. Woolard, "“making it real": exploring the potential of augmented reality for teaching primary school science," Virtual Reality, vol. 10, no. 3, pp. 163-174, 2006.

[42] G. Salvador-Herranz, D. Pérez-López, M. Alcañiz, and M. Contero, "Augmented reality at the primary school: A pilot study on a natural sciences course," in Across Spaces Workshop, European Conference-Technology Enhanced Learning, Palermo, Italy, September 2011.

[43] J. Martín-Gutiérrez, "Generic user manual for maintenance of mountain bike brakes based on augmented reality," in 28th International Symposium on Automation and Robotics in Construction, ISARC 2011, Seoul, Korea, June-July 2011, pp. 1401-1406.

[44] C. Fernández-Panadero and C. Delgado Kloos, "PhyMEL. a framework to integrate physical, mental and emotional learning in meaningfull experiences and multidimensional reports," in 3rd European Immersive Education Summit (EiED'13), London, UK, November 2013, pp. 203-208.

[45] J. Rouillard and M. Laroussi, "PerZoovasive: Contextual pervasive QR codes as tool to provide an adaptive learning support," in Proceedings of the 5th International Conference on Soft Computing As Transdisciplinary Science and Technology, ser. CSTST '08. Paris, France: ACM, October 2008, pp. 542-548.

[46] A. Kurti, D. Spikol, and M. Milrad, "Bridging outdoors and indoors educational activities in schools with the support of mobile and positioning technologies," International Journal of Mobile Learning and Organisation, vol. 2, no. 2, pp. 166-186, Jul. 2008.

[47] C. Sintoris, A. Stoica, I. Papadimitriou, N. Yiannoutsou, V. Komis, and N. Avouris, "MuseumScrabble: Design of a mobile game for children's interaction with a digitally augmented cultural space," International Journal of Mobile Human Computer Interaction (IJMHCI), vol. 2, no. 2, pp. 53-71, 2012.

[48] C. Horne, "Qrienteering: Mobilising the m-learner with affordable learning games for campus inductions," in Cases on Digital 
Game-Based Learning: Methods, Models, and Strategies, Y. Baek and N. Whitton, Eds. Hershey, PA, USA: IGI Global, 2013, pp. 97-118.

[49] M. Pérez-Sanagustín, A. Martínez, and C. Delgado Kloos, "EtiquetAR: A tool for designing tag-based mobile augmented reality experiences," Bulletin of the IEEE Technical Committee on Learning Technology, vol. 14, no. 4, pp. 27-30, 2012.

[50] M. Pérez-Sanagustín, G. Ramirez-Gonzalez, D. Hernández-Leo, M. Muñoz-Organero, P. Santos, J. Blat, and C. Delgado Kloos, "Discovering the campus together: A mobile and computer-based learning experience," Journal of Network and Computer Applications, vol. 35, no. 1, pp. 167-188, January 2011.

[51] Q. Bonnard, H. Verma, F. Kaplan, and P. Dillenbourg, "Paper interfaces for learning geometry," in 7th European Conference of Technology Enhanced Learning, EC-TEL 2012, Saarbrücken, Germany, September 2012, pp. 37-50.

[52] P. Luff, G. Adams, W. Bock, A. Drazin, D. Frohlich, C. Heath, P. Herdman, H. King, N. Linketscher, R. Murphy, M. Norrie, A. Sellen, B. Signer, E. Tallyn, and E. Zeller, "Augmented paper: Developing relationships between digital content and paper," in The Disappearing Computer, ser. Lecture Notes in Computer Science, N. Streitz, A. Kameas, and I. Mavrommati, Eds. Springer Berlin Heidelberg, 2007, vol. 4500, pp. 275-297.

[53] J. Laviole and M. Hachet, "Papart: Interactive 3D graphics and multi-touch augmented paper for artistic creation," in IEEE Symposium on 3D User Interfaces (3DUI), Orange County, CA, USA, March 2012, pp. 3-6.

[54] W. E. Mackay, "Augmented reality: Linking real and virtual worlds: A new paradigm for interacting with computers," in International Working Conference on Advanced Visual Interfaces, ser. AVI '98. LAquila, Italy: ACM, May 1998, pp. 13-21.

[55] J. Martín-Gutiérrez, J. L. Saorín, M. Contero, M. Alcañiz, D. C. Pérez-López, and M. Ortega, "Design and validation of an augmented book for spatial abilities development in engineering students," Computers \& Graphics, vol. 34, no. 1, pp. 77-91, 2010.

[56] P. Wellner, "Interacting with paper on the digitaldesk," Communications of the ACM - Special issue on computer augmented environments: back to the real world, vol. 36, no. 7, pp. 87-96, Jul. 1993.

[57] S. Yuen, G. Yaoyuneyong, , and E. Johnson, "Augmented reality: An overview and five directions for AR in education," Journal of Educational Technology Development and Exchange, vol. 4, no. 1, pp. 119-140, 2011.

[58] P. de-las Heras-Quirós, R. Román-López, R. Calvo-Palomino, J. Gato, and J. F. Gato, "Mobile augmented reality browsers should allow labeling objects. a position paper for the augmented reality on the web W3C workshop," in W3C Workshop: Augmented Reality on the Web, Barcelona, Spain, June 2010.

[59] D. J. Gagnon, "ARIS. an open source platform for developing mobile learning experiences," MSc Thesis, University of Wisconsin - Madison, December 2010.

[60] S. Kaddouci, Y. Peter, T. Vantroys, and P. Laporte, "Coupling pedagogical scenarios and location-based services for learning," Learning Technology newsletter, vol. 12, no. 4, pp. 11-14, 2010.

[61] D. Stevense and P. van der Tak, "iBetelgeuse: An augmented reality browser for iphone," Bachelor's Project, Delft University of Technology, 2010.

[62] H. Ogata, M. Li, B. Hou, N. Uosaki, M. M. El-Bishouty, and Y. Yano, "Scroll: Supporting to share and reuse ubiquitous learning logs in the context of language learning," Research and Practice in Technology Enhanced Learning, vol. 6, no. 2, pp. 69-82, 2011.

[63] R. Koper, "An introduction to learning design," in Learning Design. A Handbook on Modelling and Delivering Networked Education and Training, R. Koper and C. Tattersall, Eds. Springer, 2005.

[64] E. Villasclaras-Fernández, D. Hernández-Leo, J. I. Asensio-Pérez, and Y. Dimitriadis, "Web collage: An implementation of support for assessment design in cscl macro-scripts," Computers $\mathcal{E}$ Education, vol. 67, pp. 79 - 97, 2013.

[65] P. Sobreira and P. Tchounikine, "A model for flexibly editing CSCL scripts," International Journal of Computer-Supported Collaborative Learning, vol. 7, no. 4, pp. 567-592, 2012.

[66] D. Laurillard, P. Charlton, B. Craft, D. Dimakopoulos, D. Ljubojevic, G. Magoulas, E. Masterman, R. Pujadas, E. A. Whitley, and K. Whittlestone, "A constructionist learning environment for teachers to model learning designs," Journal of Computer Assisted Learning, vol. 29, no. 1, pp. 15-30, 2013.
[67] L. P. Prieto, J. I. Asensio-Pérez, J. A. Muñoz-Cristóbal, Y. Dimitriadis, I. M. Jorrín-Abellán, and E. Gómez-Sánchez, “Enabling teachers to deploy CSCL designs across multiple distributed learning environments," IEEE Transactions on Learning Technologies, vol. 6, no. 4, pp. 324-336, 2013.

[68] L. Li, Y. Zheng, H. Ogata, and Y. Yano, "A framework of ubiquitous learning environment," in The Fourth International Conference on Computer and Information Technology (CIT 2004), Wuhan, China, September 2004, pp. 345-350.

[69] B. Butchart, "Augmented reality for smartphones," JISC Observatory, TechWatch Report 1.1, 2011. [Online]. Available: http://opus.bath.ac.uk/34847/

[70] J. Grubert, T. Langlotz, and R. Grasset, "Augmented reality browser survey," Institute for Computer Graphics and Vision, Graz University of Technology, Austria, Technical Report ICGTR-1101, 2011. [Online]. Available: http://citeseerx.ist.psu.edu/ viewdoc/summary?doi=10.1.1.395.777

[71] C. Alario-Hoyos and S. Wilson, "Comparison of the main alternatives to the integration of external tools in different platforms," in International Conference of Education, Research and Innovation, ICERI 2010. Madrid, Spain: IATED, November 2010, pp. 3466-3476.

[72] C. Alario-Hoyos, M. L. Bote-Lorenzo, E. Gómez-Sánchez, J. I. Asensio-Pérez, G. Vega-Gorgojo, and A. Ruiz-Calleja, "Glue!: An architecture for the integration of external tools in virtual learning environments," Computers \& Education, vol. 60, no. 1, pp. 122-137, 2013.

[73] I. M. Jorrín-Abellán and R. E. Stake, “Does ubiquitous learning call for ubiquitous forms of formal evaluation? An evaluand oriented responsive evaluation model," Ubiquitous Learning: An International Journal, vol. 1, no. 3, pp. 71-82, 2009, common Ground Publisher, Melbourne, Australia.

[74] R. E. Stake, Standards-Based and Responsive Evaluation. Thousand Oaks, CA, USA: SAGE Publications Inc, 2004.

[75] W. J. Orlikowski and J. J. Baroudi, "Studying information technology in organizations: Research approaches and assumptions," Information Systems Research, vol. 2, no. 1, pp. 1-28, 1991.

[76] M. B. Miles and A. M. Huberman, Qualitative Data Analysis. An Expanded Sourcebook. Thousand Oaks, CA, USA: SAGE Publications Inc, 1994.

[77] E. G. Guba, "Criteria for assessing the trustworthiness of naturalistic inquiries," Educational Communication and Technology, vol. 29, no. 2, pp. 75-91, 1981.

[78] J. A. Muñoz-Cristóbal, J. I. Asensio-Pérez, A. Martínez-Monés, L. P. Prieto, I. M. Jorrín-Abellán, and Y. Dimitriadis, "Bucketserver: A system for including teacher-controlled flexibility in the management of learning artifacts in across-spaces learning situations," in Tenth European Conference on Technology Enhanced Learning (EC-TEL 2015), Toledo, Spain, September 2015.

[79] J. A. Muñoz-Cristóbal, M. J. Rodríguez-Triana, V. Gallego-Lema, H. F. Arribas-Cubero, A. Martínez-Monés, and J. I. AsensioPérez, "Toward the integration of monitoring in the orchestration of across-spaces learning situations," in Cross-LAK Workshop on Learning Analytics Across Physical and Digital Spaces, 6th International Learning Analytics and Knowledge Conference, LAK 2016, Edinburgh, UK, April 2016.

[80] M. J. Rodríguez-Triana, A. Martínez-Monés, and S. VillagráSobrino, "Learning analytics in small-scale teacher-led innovations: Ethical and data privacy issues," Journal of Learning Analytics, vol. 3, no. 1, pp. 43-65, 2016.

[81] J. A. Muñoz-Cristóbal, L. P. Prieto, J. I. Asensio-Pérez, I. M. Jorrín-Abellán, A. Martínez-Monés, and Y. Dimitriadis, "Sharing the burden: Introducing student-centered orchestration in acrossspaces learning situations," in 8th European Conference on Technology Enhanced Learning (EC-TEL 2013), Paphos, Cyprus, September 2013, pp. 621-622.

[82] A. Ortega-Arranz, J. A. Muñoz-Cristóbal, A. Martínez-Monés, M. L. Bote-Lorenzo, and J. I. Asensio-Pérez, "A system for gamifying ubiquitous learning situations supported by multiple technologies," in 13th International Conference on Intelligent Tutoring Systems, ITS 2016, Zagreb, Croatia, June 2016. 


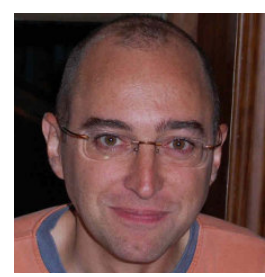

Juan A. Muñoz-Cristóbal received the Ph.D. degree in information and telecommunications technologies from the University of Valladolid, Spain, in 2015. He is currently researcher in the GSIC/EMIC group at the University of Valladolid. His research interests include the orchestration of ubiquitous learning environments and the application of augmented reality and virtual worlds in education.

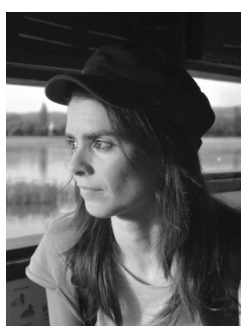

Vanesa Gallego-Lema received the Ph.D. degree in education from the University of Valladolid, Spain, in 2016. She is currently a collaborator researcher of the group GSIC/EMIC at the University of Valladolid. She worked as a teacher in Primary Education and University, and she also collaborated in training and innovation tasks at the University of Valladolid. Her research interests include the ubiquitous learning in initial teacher training focus on the teaching-learning process, and the teacher training in physical activities in the natural environment..

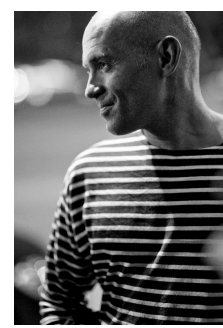

Higinio F. Arribas-Cubero received the Ph.D. degree in education from the University of Valladolid, Spain, in 2008. He is currently associate professor of didactics of the corporal expression in the Faculty of Education and Social Work at the University of Valladolid. His current research interests include the education in the leisure of different social groups, the teacher training in physical activities in the natural environment, and the physical education with groups in risk of social exclusion.

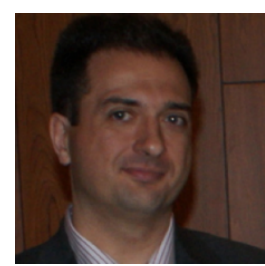

Juan I. Asensio-Pérez received the Ph.D. degree in telecommunications engineering from the University of Valladolid, Spain, in 2000. $\mathrm{He}$ is currently associate professor of telematics engineering at the University of Valladolid. His research interests within the field of Technology-Enhanced Learning include: learning design, Computer-Supported Collaborative Learning (CSCL) orchestration, and the application of Augmented Reality technologies for the tual and physical spaces. support of CSCL situations across multiple vir-

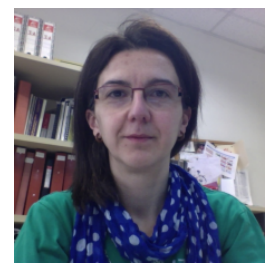

Alejandra Martínez-Monés received the Ph.D. degree from the University of Valladolid, Spain, in 2003. She is an associate professor of Computer Science at the University of Valladolid. Her research interests in the field of TechnologyEnhanced Learning relate to how to use computers to support teachers and students in the orchestration of innovative teaching and learning strategies, especially CSCL. 
APPENDIX

\section{SELECTION OF EXCERPTS OF EVIDENCE GATHERED IN THE EVALUATION}

Table A1

Selected excerpts of evidence related to the Topic 1 (creation and enactment)

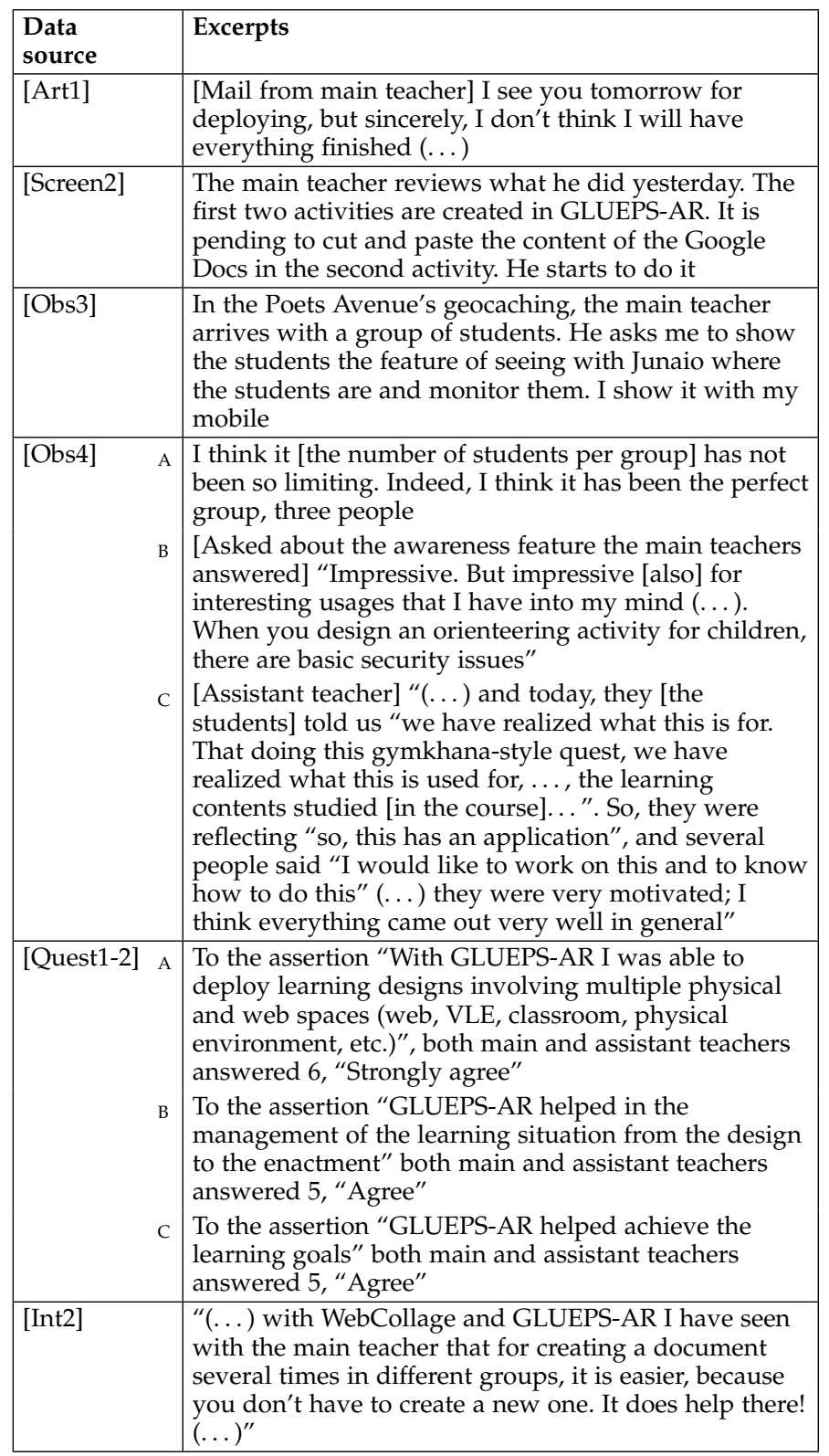

Table A2

Selected excerpts of evidence related to the Topic 2 (types of AR)

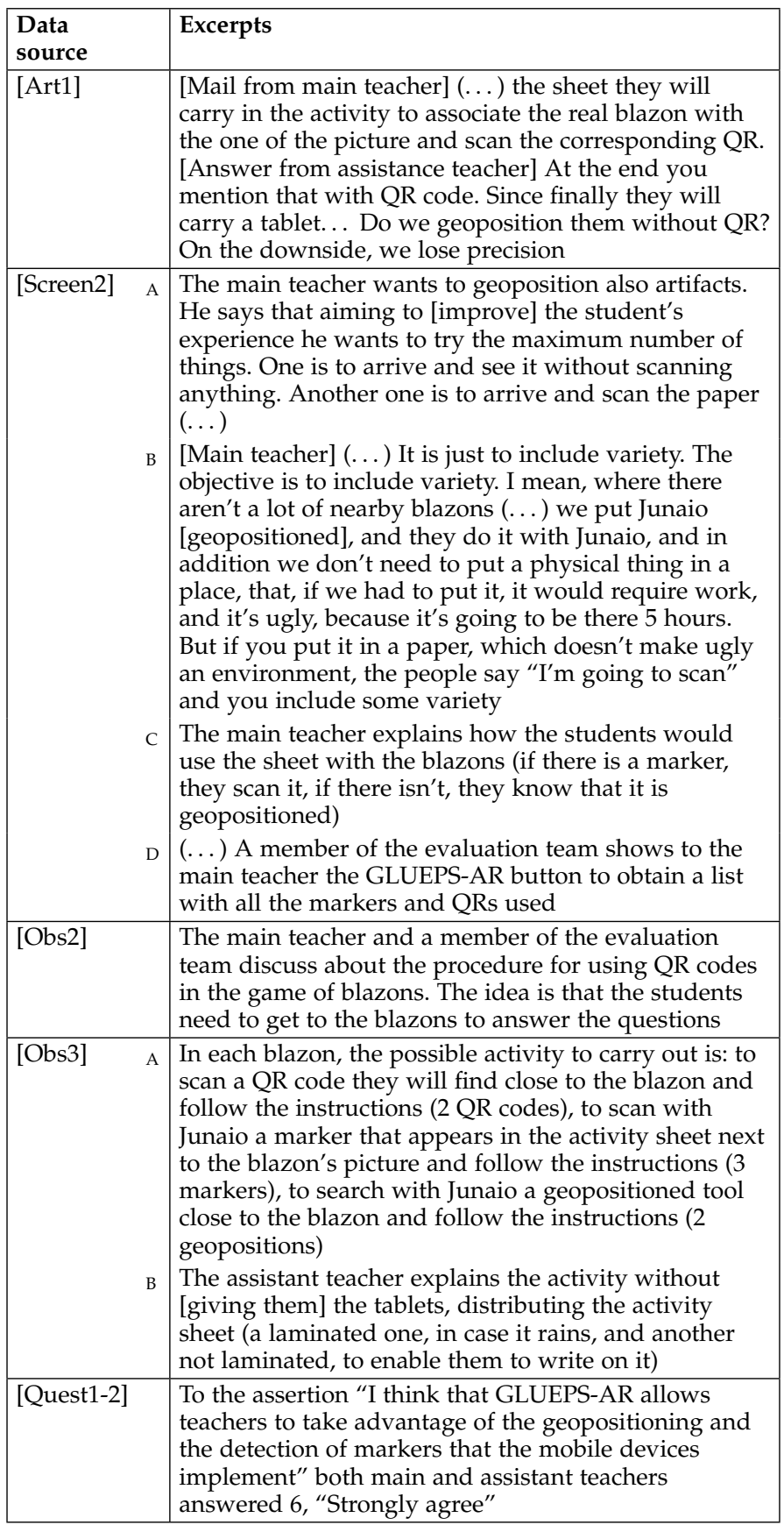


Table A3

Selected excerpts of evidence related to the Topic 3 (integration into the existing practice)

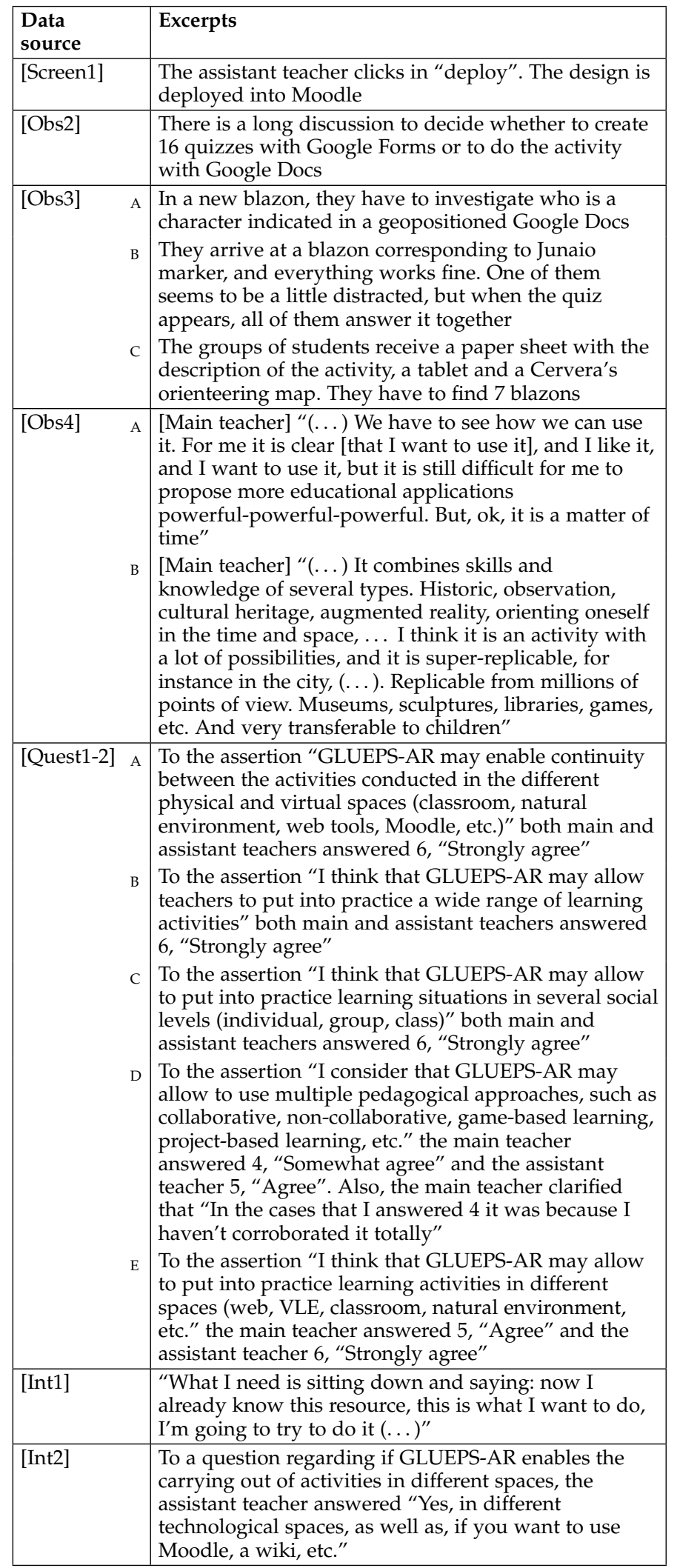

Table A4

Selected excerpts of evidence related to the Topic 4 (affordability)

\begin{tabular}{|c|c|c|}
\hline \multicolumn{2}{|l|}{$\begin{array}{l}\text { Data } \\
\text { source }\end{array}$} & Excerpts \\
\hline \multicolumn{2}{|l|}{ [Screen1] } & $\begin{array}{l}\text { [Assistant teacher] No, it is not complicated, but there } \\
\text { are some things that you have to know }(\ldots) \text { what is } \\
\text { destined to the teacher and what to the student }(. . .) \\
\text { and also, to understand all the terms }(\ldots) \text {, such as the } \\
\text { multiple positioning types... but I think that it is easy } \\
\text { to use }\end{array}$ \\
\hline \multicolumn{2}{|l|}{ [Screen2] } & $\begin{array}{l}\text { The main teacher is reusing a tool instance in the even } \\
\text { groups. At a given time, he asks if he has to do it in } \\
\text { the even or in the odd groups. It seems that the } \\
\text { repetitive operations bore him }\end{array}$ \\
\hline \multicolumn{2}{|l|}{ [Obs1] } & $\begin{array}{l}\text { [Main teacher after using GLUEPS-AR] "Yes, I see this } \\
\text { part very easy" }\end{array}$ \\
\hline \multicolumn{2}{|l|}{ [Obs3] } & $\begin{array}{l}\text { Another group arrives. They say that Junaio doesn't } \\
\text { work. I look at it, and it is because instead of being in } \\
\text { the correct Junaio channel, they are connected to a } \\
\text { Chinese one. I tell them how to detect it and solve it }\end{array}$ \\
\hline \multirow[t]{3}{*}{ [Quest1-2] } & A & $\begin{array}{l}\text { To the assertion "I think that GLUEPS-AR is easy to } \\
\text { use for non-ICT-expert teachers", the main teacher } \\
\text { answered 3, "Somewhat disagree", and the assistant } \\
\text { teacher answered 2, "Disagree" }\end{array}$ \\
\hline & B & $\begin{array}{l}\text { To the assertion "I think that the time devoted to the } \\
\text { deployment using GLUEPS-AR was affordable", the } \\
\text { main teacher answered 4, "Somewhat agree", and he } \\
\text { specified that "Maybe with more training in } \\
\text { GLUEPS-AR, which we have used very little, my } \\
\text { answer would be different" }\end{array}$ \\
\hline & C & $\begin{array}{l}\text { To the assertion "I would use GLUEPS-AR in my } \\
\text { educational practice", the main teacher answered 5, } \\
\text { "Agree", and the assistant teacher answered 4, } \\
\text { "Somewhat agree" }\end{array}$ \\
\hline \multirow[t]{2}{*}{ [Int1] } & A & $\begin{array}{l}\text { [Asked about if GLUEPS-AR is easy to use] "I go back } \\
\text { to the training. To the training, and to the raising of } \\
\text { awareness" }\end{array}$ \\
\hline & B & $\begin{array}{l}\text { "(...) the problems to implement this are the available } \\
\text { time, or the difficulty, or the skills that each teacher } \\
\text { has with this kind of things" }\end{array}$ \\
\hline \multirow[t]{3}{*}{ [Int2] } & A & $\begin{array}{l}\text { "With respect to the GLUEPS-AR [user interface], I } \\
\text { haven't used it a lot, and due to it, maybe it seems to } \\
\text { be more difficult to me. But I saw with the main } \\
\text { teacher that, in a moment, once you got it, it is the } \\
\text { same design, so you just copy } 20 \text { times and you have } \\
\text { it, it is not complicated. Then, you deploy it and here } \\
\text { it goes" }\end{array}$ \\
\hline & B & $\begin{array}{l}\text { "At the beginning, it is going to be super-strange for } \\
\text { the teachers. And afterwards, it depends on the } \\
\text { technological competence of each teacher" }\end{array}$ \\
\hline & C & $\begin{array}{l}\text { "If I have to start with WebCollage, I think that the } \\
\text { process is too long" }\end{array}$ \\
\hline
\end{tabular}

